\title{
COVID-19 restrictions and greenhouse gas savings in selected Islamic and MENA countries: An environmental input-output approach for climate policies
}

\author{
Mahdi Ghaemi AsI ${ }^{1}$ (D) Sajad Rajabi ${ }^{2}$ Muhammad Irfan ${ }^{3} \cdot$ Reza Ranjbaran $^{2}$. \\ Mohammad Ghasemi Doudkanlou ${ }^{4}$
}

Received: 20 August 2021 / Accepted: 26 November 2021 / Published online: 17 January 2022

(C) The Author(s), under exclusive licence to Springer Nature B.V. 2021

\begin{abstract}
As addressed by many studies, greenhouse gas has a significant impact on the different aspects of life and more importantly on the whole environment. The excessive emission of green gas leads to climate change which is regarded as one of the most significant challenges of 21 century. Hence, in this regard, this paper has addressed the changing greenhouse gas (GHG) emissions in 18 countries of the MENA region. For this purpose, ten different scenarios of this disease's future status and its restrictions were considered in an input-output modelling framework. The empirical results indicated that the emission of greenhouse gas is reduced under all scenarios. However, some countries experience more reduction due to the restriction because of COVID-19 like Syria, Iran, Yemen and Lebenon. Based on the ninth scenario, Iran and Syria have the highest reduction in emission of greenhouse gas by 13.1 and 13.8 per cent, and based on the tenth scenario, Lebenan and Syria will experience the highest reduction in emission by about 13.1 and 17.9 per cent. The results show that according to scenario 10 (explosive intensification of the pandemic without the wave subsiding over a while) and scenario 9 (the pandemic worsens step by step without subsiding over a while), Syria and Iran have the highest reduction
\end{abstract}

Mahdi Ghaemi Asl

m.ghaemi@khu.ac.ir

Sajad Rajabi

sajadrajabi@isu.ac.ir

Muhammad Irfan

irfanghuman77@gmail.com

Reza Ranjbaran

r.ranjbaran@isu.ac.ir

Mohammad Ghasemi Doudkanlou

m.ghasemidoudkanl@student.unisi.it

1 Faculty of Economics, Kharazmi University, No. 43, Mofatteh Ave., 15719-14911 Tehran, Iran

2 Faculty of Economics, Imam Sadiq University, Modiriat Ave, 14659-43681 Tehran, Iran

3 Department of Political Science \& International Relations, University of Gujrat, Gujrat, Pakistan

4 Department of Economics and Statistics, University of Siena, Banchi di Sotto, 55, 53100 Siena, SI, Italy 
in greenhouse gas emissions, respectively. According to scenario 1 (rapid and complete control of disease), Bahrain, Qatar, and Kuwait have the lowest reduction in GHG emissions. Besides, the study draws several fruitful implications regarding environmental concerns as sectoral analysis such as Hotels and Restaurants, Retail Trade, Fishing, Wholesale Trade, and Transport sectors. Moreover, policymakers should be alert that notwithstanding all limitations, Private Households and Public Administration develop their emissions during the pandemic since quarantine intensifies the supply of these services. Surprisingly, none of the policy restrictions have a significant impact on GHG emissions from Education, Health, and Other Services, Petroleum, Chemical, and Non-Metallic Mineral Products, Textiles and Wearing Apparel, and Re-export \& Re-import, demonstrating the robust and established nature of these sectors' activities. To control the emissions of the quarantine-neutral sectors, long- and mid-term structural and environmental policies should be considered. The researchers are guided by the novel implications in terms of how various industries might reduce emissions in different ways.

\section{Graphical abstract}

GHG emissions mitigation (from the most optimistic scenario (01) to the most pessimistic scenario (10))

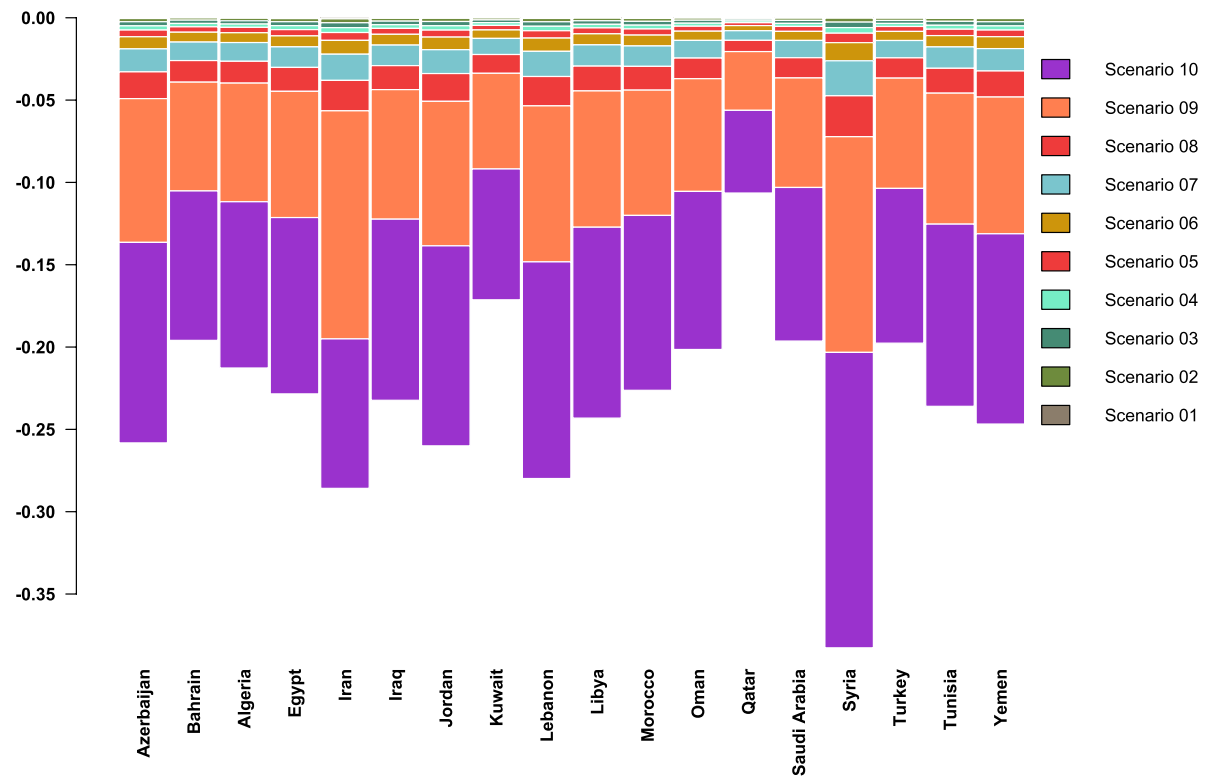

Keywords Input-output · Sector analysis · Greenhouse gases · COVID-19 · MENA · Environmental economics

\section{Abbreviations}

EU European Union

NASA National aeronautics and space administration

MENA Middle East and North Africa

EKC Environmental Kuznets Curve

OxCGRT Government response tracker index 
ISIC International standard industrial classification

Btu British thermal units

GHG Greenhouse gas

\section{Introduction}

The emission of greenhouse gas has impacted the whole world so seriously, and it is regarded as the main cause for climate change (Althor et al., 2016; Hensher, 2008; Preston \& Jones, 2006; Shen et al., 2020). Greenhouse gas is mostly produced due to energy production or consumption (Byravan et al., 2017; Kaygusuz, 2009; Lyeonov et al., 2019; Sarkodie \& Strezov, 2019). The energy is very important component for development. Hence, one may argue that reduction in may harm the development goals. In this regard, the issue of sustainable development arises. In the framework of one of the sustainable developments we actually down only focus on the present generation but we also consider the needs of future generation (Blewitt, 2012; Chichilnisky, 1997; Elliott, 2012; Rogers et al., 2012; Sachs, 2015). Moreover, many other considerations will be considered, and one of them is the emission of greenhouse gas. In this context, to achieve the sustainable development goal, we have to use the energy more efficiently and with more considerations.

Most important effects of this virus have been on the economic sectors of countries. Due to countries' economic connection and communication and receiving input from each other, all have experienced a contraction in production. The restrictions on transportation, especially between countries, have slowed global economic activities. Most importantly, fear among consumers and firms has led to changing common consumption patterns. The financial markets have also responded to these changes, and global stock indices have fallen. In this regard, we can refer to some statistics. EU industrial production index (27 countries) in the first two months of 2020 compared to the same period in 2019, reduced by about $1.3 \%$. During the same period, Malta's industrial production index increased by about $12.9 \%$, and Estonia had the lowest growth, with a reduction of $6.23 \%$ among the EU countries. The growth of the industrial production index during the first two months of 2020 was positive for $8 \mathrm{EU}$ member countries and negative for the remaining 19 countries. In the European Union, in February 2020, compared to February 2019, the production of capital goods reduced by $3.1 \%$, energy by $1.7 \%$, and intermediate goods by $0.2 \%$, while the production of low-consumption consumer goods reduced by $0.5 \%$ and durable consumer goods increased by $1.5 \%$ (Eurostat, 2020).

In addition to the negative economic consequences, significant changes were made in environmental variables. Regarding the reduction in air traffic, the shutdown of factories, and the significant reduction in road traffic, there was a beneficial effect on air pollution. Reducing coal use by power plants, refineries, and other industries reduced $\mathrm{CO}_{2}$ emissions by 250 million tonnes. NASA (National Aeronautics and Space Administration) and the European Space Agency reported a significant reduction in $\mathrm{N}_{2} \mathrm{O}$ pollution across northeast China, and the lowest mean $\mathrm{N}_{2} \mathrm{O}$ level recorded in India resulted from a nationwide travel ban at the end of March (Myllyvirta, 2020).

One of the most pressing environmental difficulties is always the reduction of emissions in parts of the world that, for various reasons, have paid less attention to pollutant emissions. One of these regions is the Middle East and North Africa (MENA). The common feature of these countries is the low mean and per capita income; at the same time, it is one of the most experienced energy production regions in the world. Therefore, it is 
evident that these countries should make more efforts for rapid economic growth through energy production and consumption. Hence, the lack of attention to environmental issues and greenhouse gas emissions will be another common feature of this region. Many studies address the trend of energy consumption in detail (Aydin et al., 2012; Aydin, 2014, 2015a, 2015b, 2015c; Azadeh \& Tarverdian, 2007; Köne \& Büke, 2010). Energy consumption has had an increasing trend and over the past decades has been doubled. By now the fossil fuels have maintained their prominent position in world primary energy consumption.

Now, considering COVID-19 pandemic in the Islamic and MENA countries and the occurrence of extensive changes in the pattern of energy production and consumption and other economic dimensions in these countries, the reduction in greenhouse gas emissions due to reduced economic activities in the MENA region is one of the most important questions of environmental researchers. This is the question that the present study intends to answer using environmental input-output data modelling and scenario design in the range from severe and complete restrictions in these countries until the complete exclusion of restrictions.

In the following, we will review studies that investigate the impact of COVID-19 on economies and the environment. Lenzen et al. (2020) estimated the economic and environmental effects of COVID-19. They considered the economic consequences of mutual government measures, resulting in reduced global production and consumption which are reinforced by global supply chains. They investigated the direct and indirect consequences of economic and social harm, as well as the effects of environmental pandemics, using a worldwide multi-regional macroeconomic model. The results show that global economic loss is $\$ 3.8$ trillion, with a pandemic 0.6 million tons of suspended particles become less than 2.5 microns and 5.1 million tons less $\mathrm{SO}_{2}$ and NOX emitted. Hassan et al. (2020) highlighted this pandemic's effects on renewable energy and investigated its environmental effects. According to his study, the outbreak caused severe problems in the renewable energy sector, such as supply chain delays, stock market problems, and the risk of not benefit from government incentives at the end of this year. The investors are not stable due to uncertainty in the sector. Hence, countries should show severe incentives for clean energy. A summary of the previous studies is provided in Table 1 .

Besides, also many studies address the level of greenhouse gas emissions. Mitra et al. (2020) attempted to investigate the level of $\mathrm{CO}_{2}$ emissions at 12 environmental sites in Calcutta. The results showed significant temporal changes in $\mathrm{CO}_{2}$ levels, but no statistically significant variation was observed among sites. Interpretation of the results due to the complete closure of industries, transportation, markets, shopping malls, leisure units, and construction, which are the primary sources of $\mathrm{CO}_{2}$ emissions, can be proven by the closure caused by COVID-19 in the city. Liberalesso et al. (2020) attempted to quantify the potential for government investment in environmentally friendly construction projects to strengthen the economy and at the same time realize the environmental achievements by reducing energy use and emitting related greenhouse gases. This analysis uses a computable general equilibrium model to investigate the macroeconomic effect of the COVID-19 crisis on a small open economy (Belgium). The proposed policy's effect is then evaluated via comparative analysis for macroeconomic parameters and $\mathrm{CO}_{2}$ equivalent emissions for the four scenarios. The results show that the COVID-19 pandemic is significantly affecting economies. However, the reduction in emissions is less than proportionate. However, welldesigned public policies can reverse this trend, leading to economic growth and a disproportionate reduction in emissions.

Moreover many other studies investigate the emission of Greenhouse gas from sectors and countries, including (Berhe et al., 2020; Ding et al., 2017; Küstermann et al., 2008; 


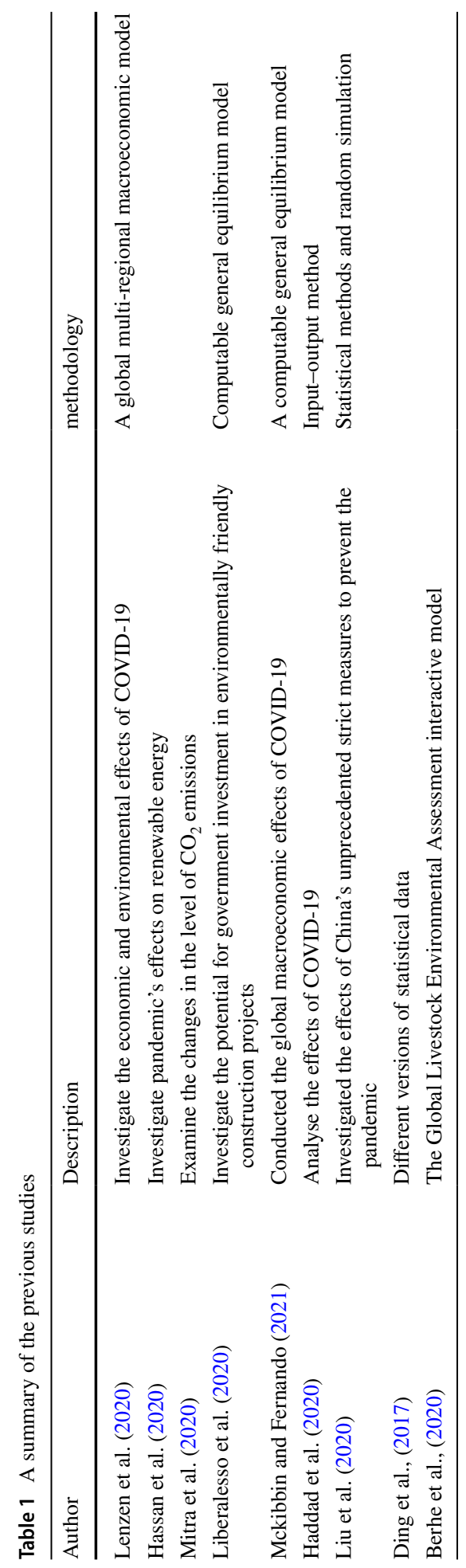


Kyung et al., 2015; Li et al., 2021; Monteith et al., 2005; Ståhl et al., 2014). For instance (Ding et al., 2017) estimated GHG emissions of China from 1990 to 2013 using different versions of statistical data are and (Berhe et al., 2020) investigated the emission in different production systems using Global Livestock Environmental Assessment interactive model.

By COVID-19 pandemic, economic studies on this disease have been expanding, which we will introduce the most critical cases in the following. McKibbin and Fernando (2021) conducted the global macroeconomic effects of COVID-19 in seven scenarios. Hence, the outbreak of a virus called COVID-19 has disrupted China's economy and spread worldwide. The pattern of the spread of this disease and its economic effect is very unclear and makes it difficult for policymakers to formulate an appropriate macroeconomic policy response. To better understand the potential economic consequences of COVID-19, this paper investigates seven different scenarios of how COVID-19 will spread next year using a modelling technique developed by L and Mc (2003). This study investigates the effects of different scenarios on macroeconomic outcomes and financial markets in a computable general equilibrium model. The scenarios studied in this paper show that even the prevalence of this disease currently can significantly affect the global economy in the short term. These scenarios show how much the disease's cost can be avoided by investing more in public health systems in all economies, especially in less developed economies with less developed healthcare systems and high population densities.

More recently, Haddad et al. (2020) attempted to analyse the effects of COVID-19 using the input-output method. This report is based on the partial hypothetical extraction approach for input-output analyses. The purpose of this report is to inform regional and national governments in Brazil and Colombia about the potential economic costs of various closure strategies at the regional and sectoral levels. The results of simulating scenarios under different hypotheses about the periods and intensity of control measures can be used after the decline in the growth rate of new patients to design regional and partial policies to facilitate closure measures used against the spread of the virus. In the same line, Liu et al. (2020) investigated the effects of China's unprecedented strict measures to prevent the pandemic. Using the published data, they estimated the model parameters using statistical methods and random simulation and determined the parameters' values to obtain the simulation test's best results. At the next stage, they used their model to quantitatively predict future pandemic developments in China under different pandemic control strategies, focusing on analysing the results' sensitivity to selecting different parameters. The study results indicate that if strict quarantine measures are continued, the number of patients in the peak state will be in the range of 52,438 to 64,090 , and its peak date will be from February 7 to February 19, 2020, and during March 18-30, 2020, the pandemic is under control. The complete control of the disease will occur from August 20 to September 1, 2020. Quarantine measures are the most effective technique for controlling the pandemic, according to sensitivity analysis. Long-term simulations and sensitivity analysis conducted in China revealed that this model is stable and empirically proven. It is proposed that this model be used to forecast the spread of the pandemic in other areas or nations. According to the study results in China, quarantine measures could not be reduced before the end of March 2020. The results also showed that China could completely resume production from April 2020 with appropriate measures against the pandemic. However, the government should act decisively against the disease's outbreak and take timely quarantine measures, although these measures may have negative and short-term public and economic consequences (Iqbal et al., 2021; Shahzad, et al., 2020a, 2020b, 2020c).

We intended to analyse the impact of the COVID-19 pandemic on the emission of greenhouse gas of selected Islamic and MENA countries by employing input-output 
framework under different scenarios. The model that we use is the novel model to find the general equilibrium. Our results indicated that the restrictions in terms of COVID-19 have an effective impact on the reduction of greenhouse gas emission during the COVID-19 period. This paper is the first study to address the impact of COVID-19 restrictions on the greenhouse gas emission. The results indicated that the emission of greenhouse gas will decrease in terms of COVID-19 restrictions in all countries and based on every scenario. Besides, the emission greenhouse gas will also be reduced from most of the sectors except some sectors including "Private Households" and "Public Administration. In the following, a review of the theoretical framework is provided. OxCGRT index is introduced to measure governments' response to the prevalence of COVID-19 and countries' restrictions to provide the theoretical foundation for scenarios. An explanation of the material and methods is presented in Sect. 3. Besides, the scenarios used, and the MENA region's model results are reported in the fourth section. Finally, in the fifth section, the authors summarize the results and implications of modelling.

\section{Theoretical support}

The primary sources of economic shocks during a pandemic can be summarized in three factors: the shock caused by the diseases of the persons, the economic effects of public and private actions such as the closure of schools and factories, travel restrictions and quarantine, and the psychological effects of a disease outbreak.

COVID-19 pandemic has many effects on the world economy; consequently, on countries' economies, which will affect the economy in three ways, which we will explain below.

\subsection{Supply shocks}

Supply shocks are more-tangible. The direct effect on supply and human responses to the virus can be seen in cases such as the closure of schools, companies, and offices. Following sporadic reports of COVID-19 cases, many large Japanese companies have instructed their employees to continue working at home. This practice spread rapidly. From an economic point of view, these travel closures and bans directly reduce productivity, as they somehow temporarily reduce employment.

Many things today can be done remotely using digital technology and software based on cloud computing and databases. However, human presence in the workplace is vital to handling tasks requiring a direct and physical presence. A Japanese healthcare manufacturer has decided to implement remote work for all its employees, but factory workers are exempt from this requirement to meet the growing demand for medical masks. Other public health measures to reduce the prevalence of the disease-such as school closuresindirectly reduce employment because workers are forced to stay home to care for their children. Japan closed all schools for one month on February 27, 2020; Italy did the same on March 4, 2020, and the process is moving fast because child-to-child transmission is the main route of transmission for the disease. Another indirect factor in the temporary reduction in employment is the absence of those who do not go to work to care for their sick relatives. This is due to the current policy of quarantining the families of those affected and those in contact with them. The severity of these supply shocks increases when it comes to healthcare workers. For example, a hospital in one of Japan's provinces with the highest 
number of COVID-19 patients was forced to reject outpatients due to the absence of nurses staying at home to care for their children.

\subsection{Supply chain shocks}

Till early March 2020, the COVID-19 pandemic was concentrated in China, accounting for more than $90 \%$ of all reported cases. Japan and Korea are next. These countries play an essential role in the global supply chains of many products.

As a global workshop, China is one of the global trade network centres, so disrupting its production will lead to secondary supply shocks in the manufacturing sector in almost all countries. Given the strong regional dimension of supply chains and the fact that China, Korea, and Japan are among the five countries most affected by the virus, the supply chain shock will be felt strongly in Asia.

Germany is the centre of European network and the seventh country to suffer the most virus damage in the world since March 5, 2020. It is clear that the pandemic's supply chain is most likely the main source of Europe's economic crisis pandemic. The same is true of North America. The United States ranks first in terms of mortality (delayed and limited testing in the United States means that the death rate there is much higher than the official figures compared to other countries; according to official statistics, the death rate in the United States is about twice as much as China and Italy). India, as the seventh-largest economy in the world, is less involved in supply chains and maybe somewhat protected from this kind of economic crisis pandemic. However, these network relationships seem very different for different sectors. Hence it is better not to generalize it too much and follow the sector analysis.

\subsection{Demand shocks}

Demand shocks due to COVID-19 can be distinguished from both practical and psychological aspects. The practical shock means that some customers refuse to enter the store, and similarly, some door-to-door services are suspended so that customers will have less access to the goods. The psychological shock is that customers and companies tend to take the "caution and patience" approach in the face of uncertainty over the COVID-19 pandemic, such as the 2008 crisis. In past crises, such as the Great Depression of 2008-2009, persons and companies refused to buy and delayed investing. This can be detrimental, significantly, when international media and individuals' communications can simultaneously and unintentionally induce such beliefs. To put it another way, the shock of "caution and patience" is sweeping the Internet. Traditional trade and bilateral finance interactions do not always follow demand shocks. These phenomena also happened during the global financial crisis of 2008-2009, when people and businesses all over the globe were impacted psychologically by the continuing financial crisis in the United States. While only a handful of countries were directly affected by high-risk loans, the US crisis's psychological shock has led persons in many countries to delay buying and investing. Thus, a financial shock in the North Atlantic became a major shock to global demand. The volume of trade and almost all productions reduced rapidly and simultaneously in all countries. Although history will not necessarily repeat this pattern in response to COVID-19 shock, this possibility cannot be ignored (Doğan et al., 2020; Shakoor et al., 2020).

Each of these demand shocks in the first round is likely to intensify under the Keynesian multiplier influence. Not working means not making money for many people and 
companies worldwide, which will be a significant obstacle to meeting their needs. Globally, countries' economies are interconnected by the cross-border circulation of goods, services, knowledge, persons, financial capital, foreign direct investment, international banking, and exchange rate (Baldwin \& Di Mauro, 2020).

\subsection{Greenhouse gases}

Conventionally, the relationship among different indicators of environmental degradation and economic development is expressed via the environmental Kuznets curve (EKC). In this regard, environmental pollution through economic development has caused damage by combining factors such as economic growth, population growth, energy use, and industrial activities (Fatima et al., 2021; Guo et al., 2021; Rafique et al., 2021) According to Grossman and Kruger studies, the relationship between environment and per capita income is inverted in the form of U (Bhattacharyya, 2019; Shahzad et al., 2020a), which means that environmental vulnerability to the development of economic activities is based on static assumptions about technology and environmental investment, because as income increases, so will the demand for environmental quality improvement. In other words, in the early stages of economic growth, awareness and knowledge of environmental problems are low, not crucial. At the early stages of economic growth, environmental damage increases with income growth (Fatima et al., 2021; Shahzad et al., 2020b; Talbi et al., 2020), partly an upward trend in per capita income. Then, by increasing awareness and enforcement of environmental laws, the level of degradation reduces (Ghazouani et al., 2020, 2021; Shahzad, 2020c).

Following COVID-19 pandemic and imposing severe restrictions in various countries worldwide, the debate over the environmental effects and emissions due to the pandemic is still new and insufficiently studied. However, some argue that the COVID-19 pandemic reduces environmental pollution, and some mention another significant damage to the environment. Hence, we try to mention some of them.

\subsubsection{Negative environmental impacts of COVID-19}

The COVID-19 pandemic has led to an increase in hospital activity and increasing medical waste. Some studies show that during the peak period of the disease in Wuhan, an average of 240 tons of medical waste was generated daily in hospitals, which is six times the average amount (Zuo, 2020). Moreover, plastic-based medical masks used worldwide are another environmental problem. "Masks are made of polypropylene and are very difficult to break down in nature," said Tracey Read, founder of the Environmental Protection Agency, Seas without Plastic (CDP, 2020).

\subsubsection{Positive environmental effects of COVID-19}

One of the most important positive effects of COVID-19 pandemic is the significant reduction in greenhouse gas emissions in the world plan. According to studies, the reduction in traffic due to the closure of many industrial, scientific, and tourist centres has led to a reduction in greenhouse gas emissions. This reduction was observed in countries such as China and Italy (CDP, 2020). Furthermore, a 25\% reduction in carbon emissions was reported in China (Myllyvirta, 2020). A significant reduction was observed in France and Italy's nitrogen dioxide, imaged by the Copernicus Sentinel-5P satellite during the 
Table 2 OxCGRT Indicators. Source: https://covidtracker.bsg.ox.ac.uk

\begin{tabular}{|c|c|c|c|}
\hline ID & Name & Type & Targeted/General \\
\hline \multicolumn{4}{|c|}{ Containment and closure } \\
\hline $\mathrm{C} 1$ & School closing & Ordinal & Geographic \\
\hline $\mathrm{C} 2$ & Workplace closing & Ordinal & Geographic \\
\hline $\mathrm{C} 3$ & Cancel public events & Ordinal & Geographic \\
\hline $\mathrm{C} 4$ & Restrictions on gathering size & Ordinal & Geographic \\
\hline $\mathrm{C} 5$ & Close public transport & Ordinal & Geographic \\
\hline C6 & Stay at home requirements & Ordinal & Geographic \\
\hline $\mathrm{C} 7$ & Restrictions on internal movement & Ordinal & Geographic \\
\hline $\mathrm{C} 8$ & Restrictions on international travel & Ordinal & No \\
\hline \multicolumn{4}{|c|}{ Economic response } \\
\hline $\mathrm{E} 1$ & Income support & Ordinal & Sectoral \\
\hline E2 & Debt/contract relief for households & Ordinal & No \\
\hline E3 & Fiscal measures & Numeric & No \\
\hline E4 & Giving international support & Numeric & No \\
\hline \multicolumn{4}{|c|}{ Health systems } \\
\hline H1 & Public information campaign & Ordinal & Geographic \\
\hline $\mathrm{H} 2$ & Testing policy & Ordinal & No \\
\hline $\mathrm{H} 3$ & Contact tracing & Ordinal & No \\
\hline $\mathrm{H} 4$ & Emergency investment in healthcare & Numeric & No \\
\hline H5 & Investment in COVID-19 vaccines & Numeric & No \\
\hline \multicolumn{4}{|c|}{ Miscellaneous } \\
\hline M1 & Other responses & Text & No \\
\hline
\end{tabular}

pandemic and a year earlier (ESA, 2020). During the pandemic, air pollution has reduced. There are also many other studies on reducing pollution in different countries.

\subsection{Government response tracker index (OxCGRT)}

To combat the COVID-19 epidemic, countries have taken considerable efforts. Measuring governments' success against the coronavirus throughout the globe and looking into their experiences may help manage and combat the virus. Based on OxCGRT, the data are collected by large groups of researchers from publicly available sources such as newspapers, press releases, and government meetings and recorded according to a specific standard. The collected data are reported in the form of 18 indicators, which can be seen in Table 2 (Hale, Petherick, et al., 2020; Hale, Webster et al., 2020):

\subsection{Research scenarios}

Using Government Response Tracker Index (OxCGRT) for 18 countries in the MENA region and one period of time (in this article, based on the nature of Input-Output tables, one year is considered) is considered the initial shocks to these economies, and their effects on the economic sectors of these countries will be studied. To calculate the effects of these shocks by considering the types of direct, indirect, and total relationships in economies, the 
Table 3 Selected countries of the MENA region. Source: World Bank, MENA Region countries

\begin{tabular}{llll}
\hline Country & Code & Country & Code \\
\hline Azerbaijan & AZE & Libya & LBY \\
Bahrain & BHR & Morocco & MAR \\
Algeria & DZA & Oman & OMN \\
Egypt & EGY & Qatar & QAT \\
Iran & IRN & Saudi Arabia & SAU \\
Iraq & IRQ & Syria & SYR \\
Jordan & JOR & Turkey & TUR \\
Kuwait & KWT & Tunisia & TZA \\
Lebanon & LBN & Yemen & YEM \\
\hline
\end{tabular}

Table 426 parts of input-output tables of the studied countries

\begin{tabular}{lllr}
\hline Sector name & Symbol & Sector name & Symbol \\
\hline Agriculture & Sector 01 & Construction & Sector 14 \\
Fishing & Sector 02 & Maintenance and repair & Sector 15 \\
Mining and quarrying & Sector 03 & Wholesale trade & Sector 16 \\
Food and beverages & Sector 04 & Retail trade & Sector 17 \\
Textiles and Wearing apparel & Sector 05 & Hotels and Restaurants & Sector 18 \\
Wood and paper & Sector 06 & Transport & Sector 19 \\
Petroleum, Chemical, and non- & Sector 07 & Post and Telecommunications & Sector 20 \\
\multicolumn{1}{c}{ metallic mineral products } & & & \\
Metal products & Sector 08 & Financial intermediation and business activities & Sector 21 \\
Electrical and machinery & Sector 09 & Public administration & Sector 22 \\
Transport equipment & Sector 10 & Education, health and other services & Sector 23 \\
Other manufacturing & Sector 11 & Private households & Sector 24 \\
Recycling & Sector 12 & Others & Sector 25 \\
Electricity, gas, and water & Sector 13 & Re-export and Re-import & Sector 26 \\
\hline
\end{tabular}

symmetric input-output Table of industry-industry in 2015 is used, which is grouped into 26 sections (Table 4). The input-output table is based on the fourth version of ISIC classification. Therefore, to establish the relationship between the input-output pattern and the types of gases, multiplier coefficients of pollution and energy footprint index published by the KGM Institute were used. The selected countries in the MENA region studied in this study are shown in Table 3 .

To compare input-output tables with each other, it is necessary to have tables with the same dimensions. In other words, the studied tables should be matched in terms of the number and nature of parts. The following equation is used for this purpose:

$$
\mathrm{H}_{\mathrm{i} \times \mathrm{j}} \times \mathrm{Y}_{\mathrm{j} \times \mathrm{j}} \times \mathrm{H}_{\mathrm{j} \times \mathrm{i}}^{\prime}=\mathrm{Y}_{\mathrm{i} \times \mathrm{i}}^{*}
$$

$\mathrm{Y}$ is the initial matrix, and $\mathrm{Y}^{*}$ is the matched matrix. Matrix $\mathrm{H}$ acts as a converter whose number of rows is equal to the number of rows of the matched matrix, and the number of columns is equal to the number of entries of the initial matrix. As a result, a matched 
matrix is obtained by reducing the number of entries of the initial matrix from $j$ to $i$. As the case may be, the elements of the conversion matrix $\mathrm{H}$ and its transposition $\mathrm{H}^{\prime}$, as the case may be, consist of zero and one. (Table 4).

To convert the n-part input-output Table to an m-part Table, first, the conversion matrix $\mathrm{H}$ is pre-multiplied by the principal matrix $\mathrm{Y}$, and then its transposition is multiplied by the product of the matrix $\mathrm{H}$ in the matrix $\mathrm{Y}$. Therefore:

$$
[H]_{n \times 7} \times\left[Y_{i j}\right]_{m \times m} \times[H]_{m \times n}=\left[Y_{i j}^{*}\right]_{n \times n}
$$

Like other modelling models in different sciences, in this study, hypotheses have also been considered that can be classified into three categories. The first category is related to input-output modelling hypotheses which were mentioned in various books and papers such as Raa, (2006), Miller and Blair (2009), and Ciaschini (1988). The second group of hypotheses points out that since 2015, the technologies for the production of economic activities in the MENA region have not changed, and in other words, the technical coefficients of the sectors are the same since 2015 to date. The third category of hypotheses is related to the coronavirus and government decisions, as it is assumed that with the intensification of the pandemic, social restrictions and bans on activity are intensified. With the reduction, the severity of the restrictions reduces. The first category of hypotheses, such as homogeneity, final exogenous demand, linear production function, etc., provides the leading platform for implementing input-output models for the model maker. The second group is considered because the MENA region countries' statistical input-output tables after 2015 are not available. The third category of hypotheses also allows the quantification of shock based on the OxCGRT index in supply and demand.

\section{Data and methodology}

In a general classification, environmental input-output modelling is divided into "hybrid sector methods" and "ecological-economic inputs and products."

According to the first type, the "hybrid sector" method analyses the environmental sector (in this study, greenhouse gases) using the input-output table. In this method, energy data in terms of British thermal units (Btu) and non-energy data in terms of currency are included in the Table. For this purpose, first the necessary matrices for this analysis are defined. $\mathrm{Z}$ matrix is an interdepartmental matrix that consists of two parts: energy carriers and non-energy materials. In this matrix, the unit of measurement for Btu energy carriers and non-energy materials is the monetary unit.

$$
Z=\left\{\begin{array}{l}
E_{z}(B t u) \text { energy carriers } \\
Z_{j}(\$) \text { non-energy materials }
\end{array}\right.
$$

For example, for a two-sector economy, we would have:

$$
Z=\left[\begin{array}{cc}
B t u & B t u \\
\$ & \$
\end{array}\right]
$$

The total output of $\mathrm{X}$ in the energy input-output matrix is defined as follows: 


$$
X=\left\{\begin{array}{l}
\mathrm{E}_{\mathrm{x}}(\mathrm{Btu}) \text { energy carriers } \\
\mathrm{X}_{\mathrm{j}}(\$) \text { non-energy materials }
\end{array}\right.
$$

For example, for a two-sector economy that has an energy sector, we have:

$$
X^{*}=\left[\begin{array}{c}
B t u \\
\$
\end{array}\right]_{2 \times 1}
$$

The final demand in the energy input-output matrix also includes two parts: monetary and btu.

$$
Y=\left\{\begin{array}{l}
E_{y}(\mathrm{Btu}) \text { energy carriers } \\
Y_{j}(\$) \text { non-energy materials materials }
\end{array}\right.
$$

Matrix F represents the sum of direct and indirect energy use.

$\mathrm{F}^{*}=$ Intersectoral energy use + final energy use

$$
F=\left\{\begin{array}{l}
F_{k}(\mathrm{Btu}) \text { energy carriers } \\
0(\$) \text { non-energy materials materials }
\end{array}\right.
$$

For example, for a two-sector economy, this matrix is as follows:

$$
F^{*}=\left[\begin{array}{c}
B t u \\
0
\end{array}\right]_{2 \times 1}
$$

Now, we calculate the matrix of Leontief A * coefficients for the energy input-output matrix using the above definitions as follows:

$$
A^{*}=Z^{*}\left(\hat{X}^{*}\right)^{-1}
$$

$\hat{X}^{*}$ matrix is a diagonal matrix in which each element of the diameter is the total output of one of the economic sectors. For example, for a two-sector economy, the matrix of Leontief coefficients would be as follows:

$$
A^{*}=\left[\begin{array}{cc}
\frac{B t u}{\$} & \frac{B t u}{\$} \\
\frac{\$}{B t u} & \frac{\$}{\$}
\end{array}\right]_{2 \times 2}
$$

Nevertheless, the properties of this matrix are different from the conventional Leontief matrix. For example, the sum of each column in matrix $A^{*}$ may not be less than one. Direct energy use is the amount of energy input that each sector receives directly from the energy sector. Direct energy use coefficients per production unit can be obtained from the following equation.

$$
\delta=F * \cdot(X *)^{-1} \cdot A *
$$

The coefficients of total energy use, including direct and indirect use, are as follows:

$$
\alpha=F * \cdot(X *)^{-1} \cdot(I-A *)^{-1}
$$

Finally, according to the emission coefficients, changes in gas emissions can be calculated. 
Table 5 Schematic model of symmetric input-output table with ecological inputs and outputs

\begin{tabular}{|c|c|c|c|c|c|c|c|c|}
\hline \multirow{2}{*}{\multicolumn{2}{|c|}{$\begin{array}{l}\text { Eco- } \\
\text { logical } \\
\text { product }\end{array}$}} & \multirow{3}{*}{$\begin{array}{l}\text { Total produc- } \\
\text { tion }\end{array}$} & \multirow[t]{3}{*}{ Final demand } & \multicolumn{5}{|c|}{ Inter-section exchange } \\
\hline & & & & \multicolumn{5}{|c|}{ Consuming sector } \\
\hline $\mathrm{CO}_{2}$ & $\mathrm{SO}_{2}$ & & & Industry & Mining & Agr & culture & \\
\hline \multirow{5}{*}{$\begin{array}{l}\mathrm{n}_{12} \\
\mathrm{n}_{22} \\
\mathrm{n}_{32}\end{array}$} & $\mathrm{n}_{11}$ & $\mathrm{x}_{1}$ & \multirow{5}{*}{$\begin{array}{l}f_{1} \\
f_{2} \\
f_{3}\end{array}$} & $a_{13}$ & $a_{12}$ & $a_{11}$ & Agriculture & \multirow[t]{3}{*}{ Producing sector } \\
\hline & $\mathrm{n}_{21}$ & $\mathrm{x}_{2}$ & & $a_{23}$ & $a_{22}$ & $a_{21}$ & Mining & \\
\hline & $\mathrm{n}_{31}$ & $\mathrm{x}_{3}$ & & $a_{33}$ & $a_{32}$ & $a_{31}$ & Industry & \\
\hline & & & & $\mathrm{m}_{13}$ & $\mathrm{~m}_{12}$ & $\mathrm{~m}_{11}$ & Oil, gas, and & \multirow[t]{2}{*}{ Ecological input } \\
\hline & & & & $\mathrm{m}_{23}$ & $\mathrm{~m}_{22}$ & $\mathrm{~m}_{21}$ & land & \\
\hline
\end{tabular}

The second type of environmental input-output modelling related to various gas emissions is ecological-economic inputs and products. This method is used in this study.

Modelling environmental issues distinguish among factors used as input in the production process, such as primary energy, land, water, and factors produced in this process, such as pollution, waste, and greenhouse gases.

These environmental factors can be used as inputs and outputs. We consider a set of ecological inputs (such as crude oil, gas, solar energy, wind energy, biomass, water, land, etc.) and show its value with $M=\left(m_{k j}\right)$ matrix. Each M matrix element reflects the value of environmental input of type $\mathrm{k}$ used in Sector $\mathrm{J}$ production.

We also consider a set of environmental outputs, such as the amount of air pollution caused by $\mathrm{SO} 2$, and denote it by the matrix $N=\left[n_{i k}\right]$. Each $\mathrm{N}$ matrix element represents the value of the ecological output of type k generated by the output of Sector i. In this case, the Table is generalized as follows (assuming the Table has three parts, two ecological inputs, including oil and gas and land, and two ecological products):

According to Table 5, the matrix of Leontief technical coefficients can be defined.

$$
A_{n \times n}=Z_{n \times n} \hat{X}_{n \times n}^{-1}
$$

where $\mathrm{Z}_{\mathrm{n}{ }^{* \mathrm{n}}}$ is the inter-section exchange matrix, and $\hat{X}_{n \times n}$ is the diameter matrix whose diameter elements are the total product of each section.

Then, we define the matrix of ecological input coefficients $R=\left[r_{k j}\right]$, which is the value of ecological commodity $\mathrm{k}$ used for one dollar of production in industry $j$.

$$
R_{k \times n}=M_{k \times n}\left(\hat{X}_{n \times n}^{-1}\right)
$$

$\mathrm{M}_{2 * 3}$ shows the inter-section exchange matrix between the two ecological goods of land and oil and gas and industry, agriculture, and mining sectors. The matrix of ecological output coefficients is defined in the same way. The elements of the matrix of ecological output coefficients $Q=\left[q_{k j}\right]$ represent the ecological output of $k$, which is produced for one dollar of the product of $\mathrm{j}$.

$$
Q_{k \times n}=N_{k \times n}^{\prime}\left(\hat{X}_{n \times n}\right)^{-1}
$$

In this case, $\mathrm{N}_{\mathrm{n} * \mathrm{k}}$ is the matrix of the final production of ecological goods produced by each economic sector. Then, the matrix of the coefficients of the total inputs and outputs of the ecological goods is calculated as a function of the final demand. First, we express the coefficient matrix of the effects of all the inputs: 


$$
\begin{gathered}
Q_{k \times n}^{*}=Q_{k \times n}(I-A)_{n \times n}^{-1} \\
R_{k \times n}^{*}=R_{k \times n}\left(I-A_{n \times n}\right)^{-1}
\end{gathered}
$$

Matrix $Q^{*}=\left[\mathrm{q}_{\mathrm{ij}}\right]$ elements show the amount of i-type pollution produced directly and indirectly in exchange for one $\$$ of final demand for section $\mathrm{j}$. The elements of the $\mathrm{R}^{*}{ }_{2 * 3}=\left[\mathrm{r}^{*} \mathrm{ij}\right]$ matrix indicate how much ecological input is directly and indirectly needed to meet the final demand for a product of Section $\mathrm{j}$. Because of the social restrictions imposed, it is necessary to consider changes in production, relationships among sectors, and the resulting shock. The total output changes and relationships among sectors are modelled via the hypothetical partial extraction method (Miller \& Blair, 2009). The partial hypothetical extraction method, which is part of the generalized hypothetical extraction method, was introduced by Dietzenbacher and Lahr (2013), pioneers of input-output modelling. As mentioned earlier, the general hypothetical extraction method has significant drawbacks. In this method, these drawbacks and problems were answered so that, first, in this method, it is assumed that $\alpha$ per cent of the intermediate input of sectors of the economy are removed for various reasons than with what is occurs in the economy, has higher compliance. Second, according to this method, there is no absolute emphasis on the matrix of intermediate effects, and the value-added vector and its changes are considered. Third, according to the partial hypothetical extraction method, it is unnecessary to reduce $\alpha$ per cent of a sector's input. However, it can be assumed that $\alpha$ per cent increases in the sectors for various reasons such as natural factors, exploration of mines and reservoirs, economic policy, etc. Fourth, in this method, supply will not be extracted; consequently, the intermediate exchange matrix will not be smaller. It should be noted that we used PyIO which is a module for Input-Output analysis, written in Python. The data has been extracted from the Eora global supply chain database which is made up of a multi-region input-output table (MRIO) model that provides a time series of high-resolution IO tables for 190 countries, along with matching environmental and social satellite accounts.

\section{Empirical results}

In this section, modelling the changes in the greenhouse gas emissions in ten scenarios in 18 countries in the MENA region are presented. ${ }^{1}$ Since the situation facing countries around the world concerning COVID-19 pandemic and the resulting restrictions is not absolute, ten different scenarios will be investigated in this paper (Table 6), and the emission status of greenhouse gases in each case was modelled. The study flow diagrams are illustrated in Fig. 1.

The modelling results are performed for all 18 countries, and the results are specified. Table 7 shows the total changes in the greenhouse gas emissions in these 18 countries. Moreover, Figs. 2, 3, 4, 5, 6, 7, 8, 9, 10, 11 (10 heatmaps) show the reduction or increase in greenhouse gas emissions in 26 sectors and the final demand of selected Islamic and MENA countries:

\footnotetext{
${ }^{1}$ The countries in MENA region which studied in this paper are as follows: Algeria, Azerbaijan, Bahrain, Egypt, Iran, Iraq, Jordan, Kuwait, Lebanon, Libya, Morocco, Oman, Qatar, Saudi Arabia, Syria, Tunisia, Turkey, and Yemen.
} 
Table 6 Ten scenarios

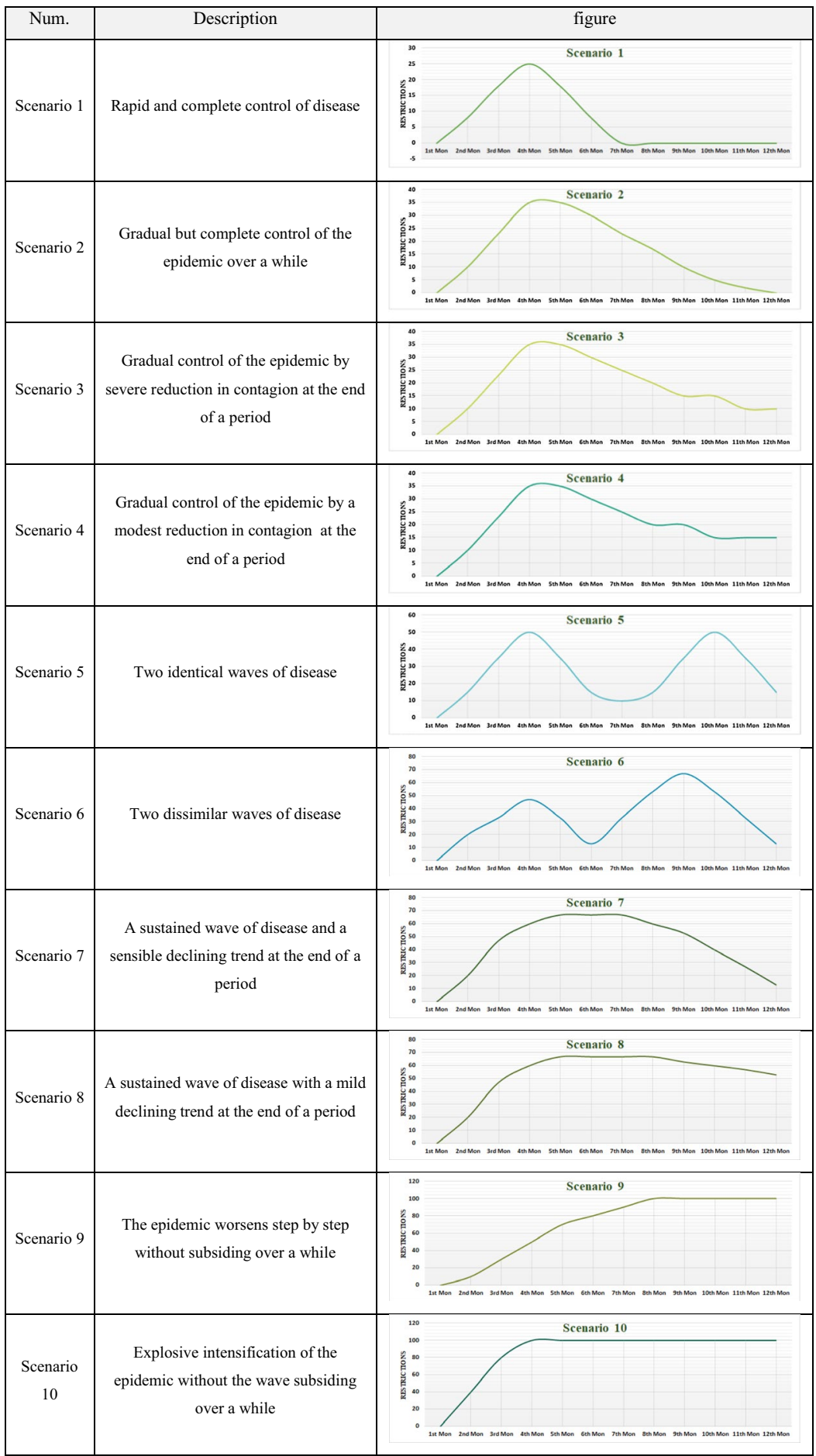



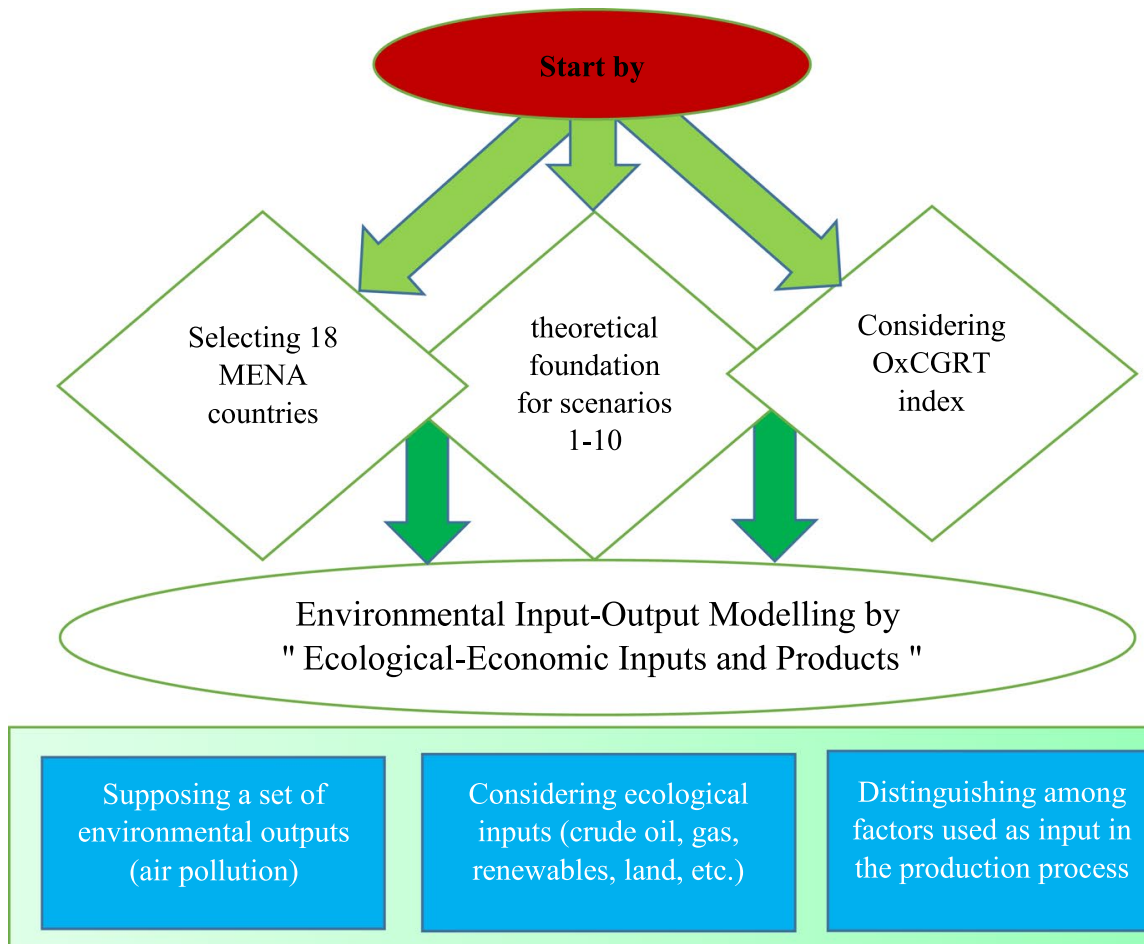

Considering ecological inputs (crude oil, gas, renewables, land, etc.)
Distinguishing among factors used as input in the production process

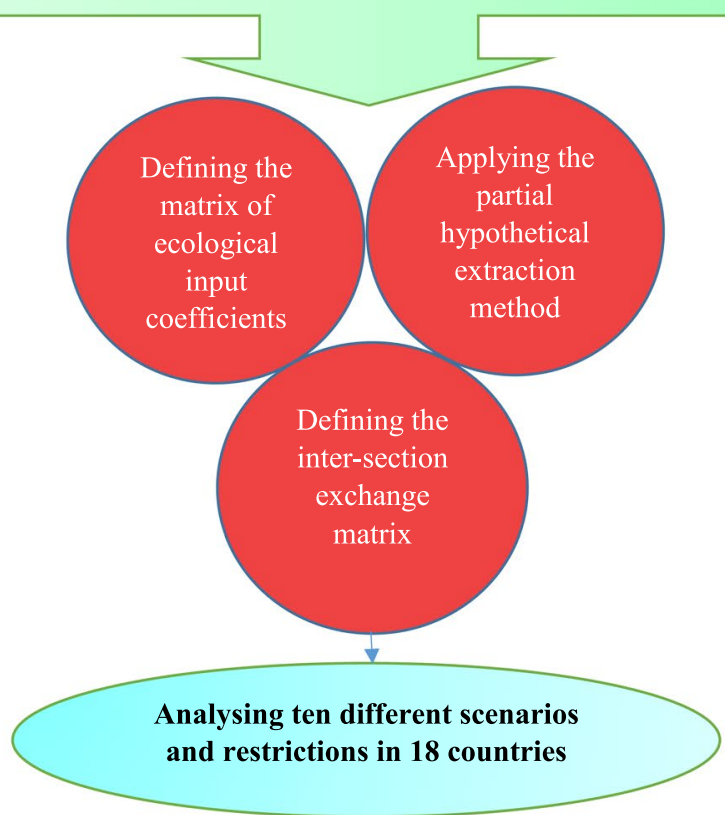

Fig. 1 Flowchart of study 


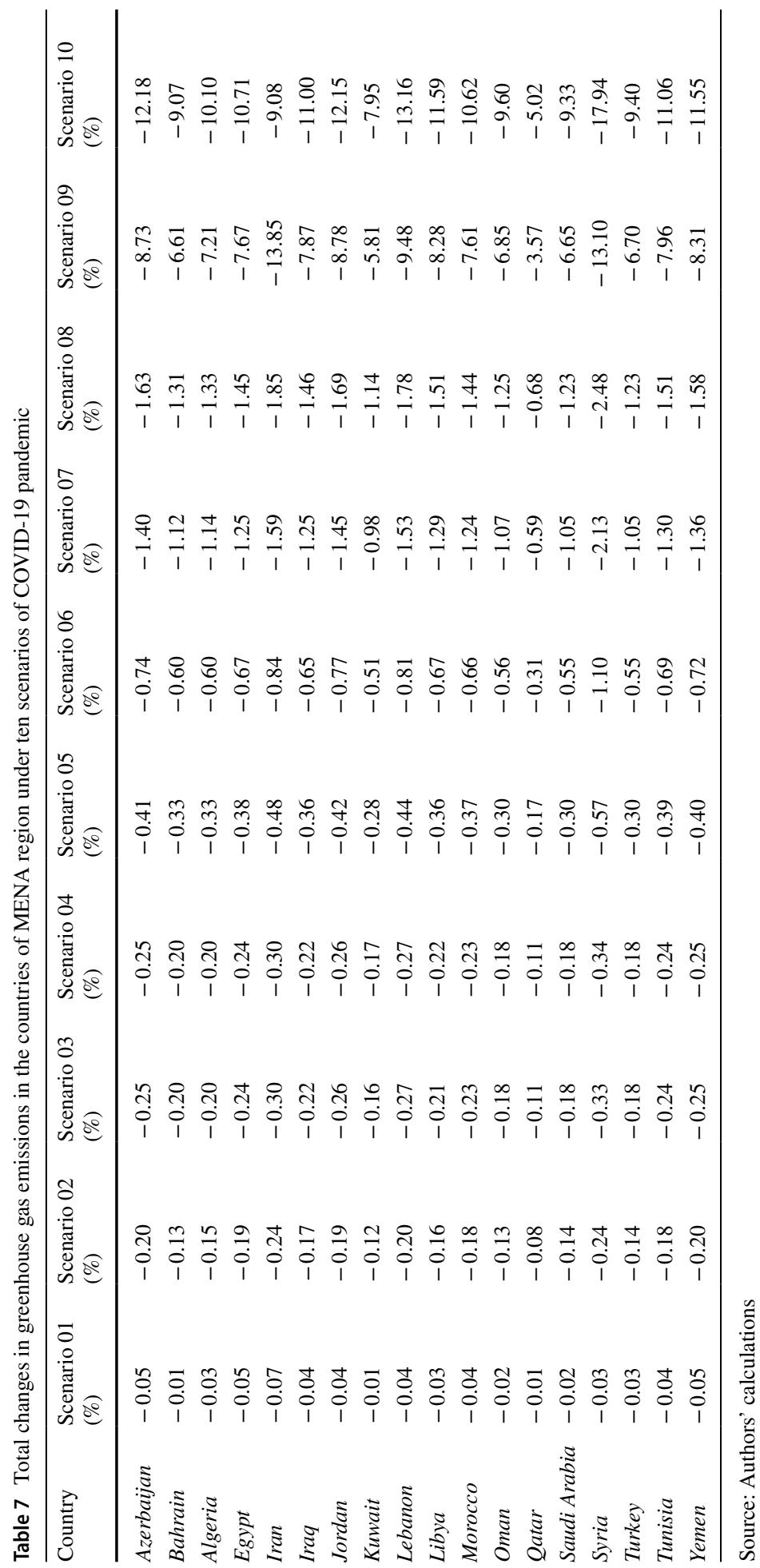




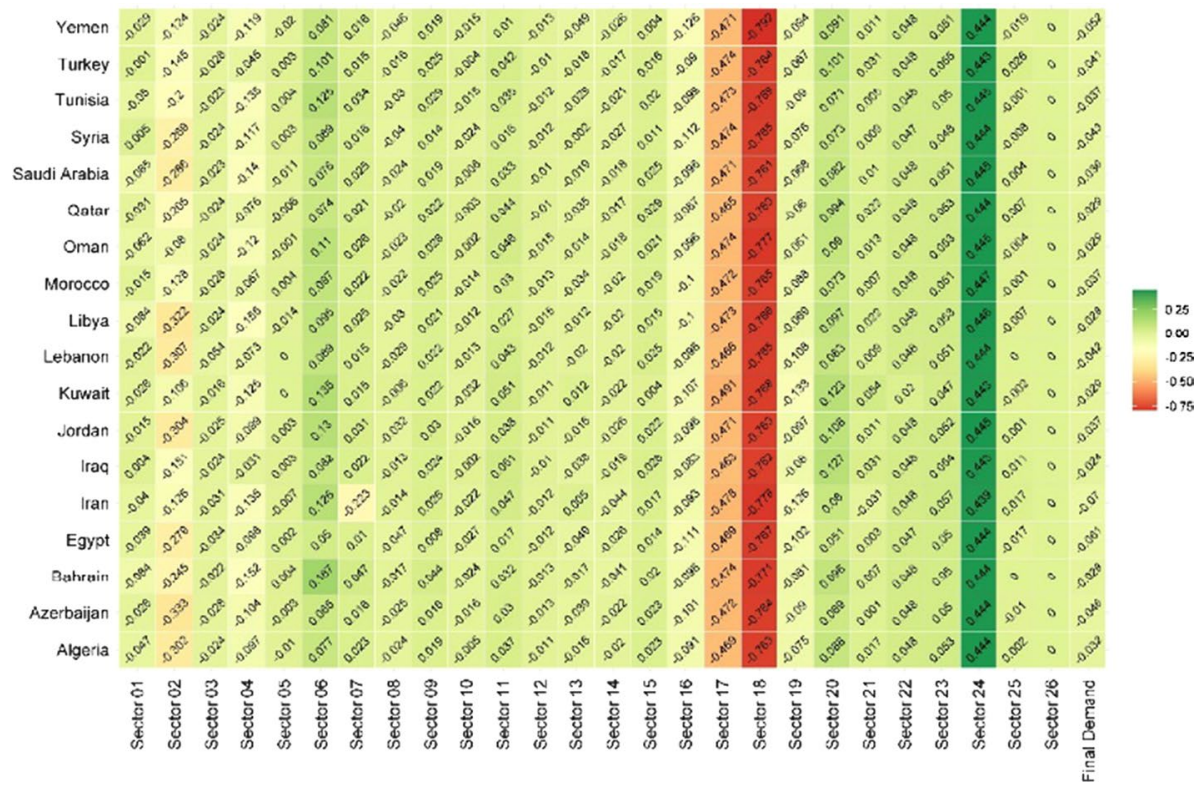

Fig. 2 Changes GHG emissions in each sector based on scenario 1. Source: Authors' calculations

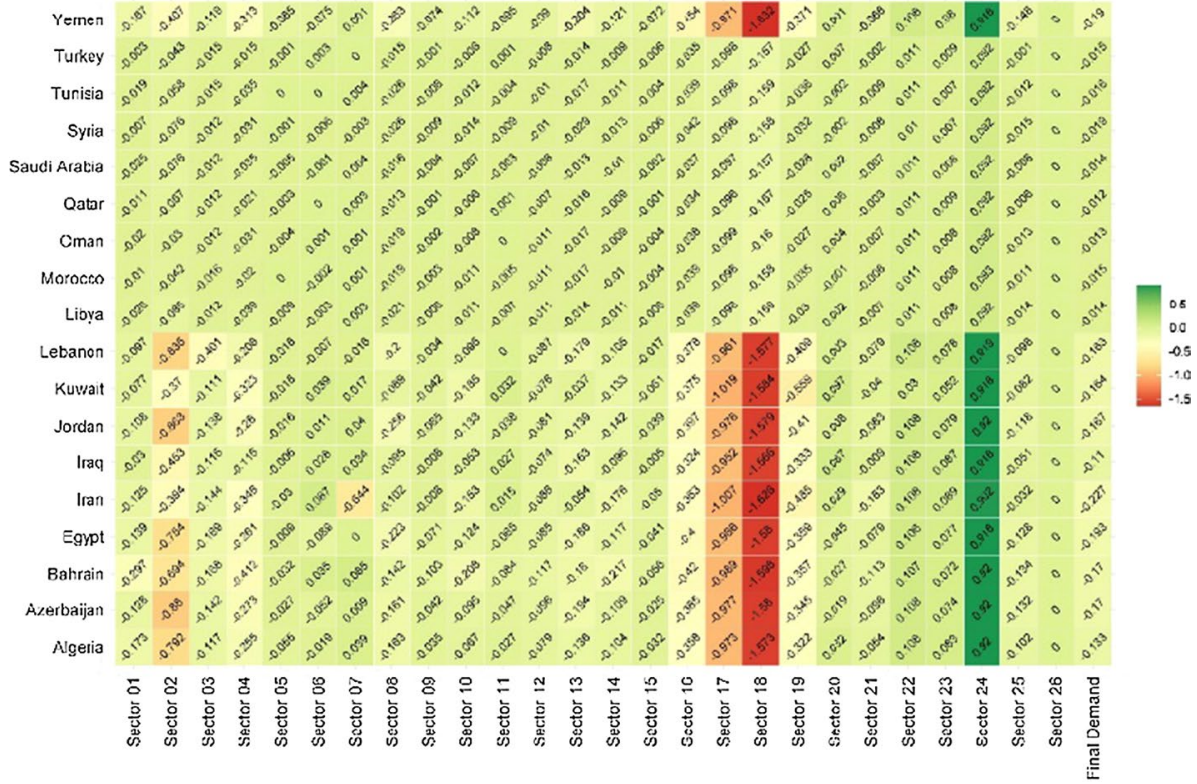

Fig. 3 Changes GHG emissions in each sector based on scenario 2. Source: Authors' calculations

At this stage, it is better to examine the results separately for each sector and compare the situation of each sector in ten scenarios, as indicated in Figs. 12, 13, 14, 15, 16, 17, 18, $19,20,21,22,23,24,25,26,27,28,29,30,31,32,33,34,35,36,37,38$. 


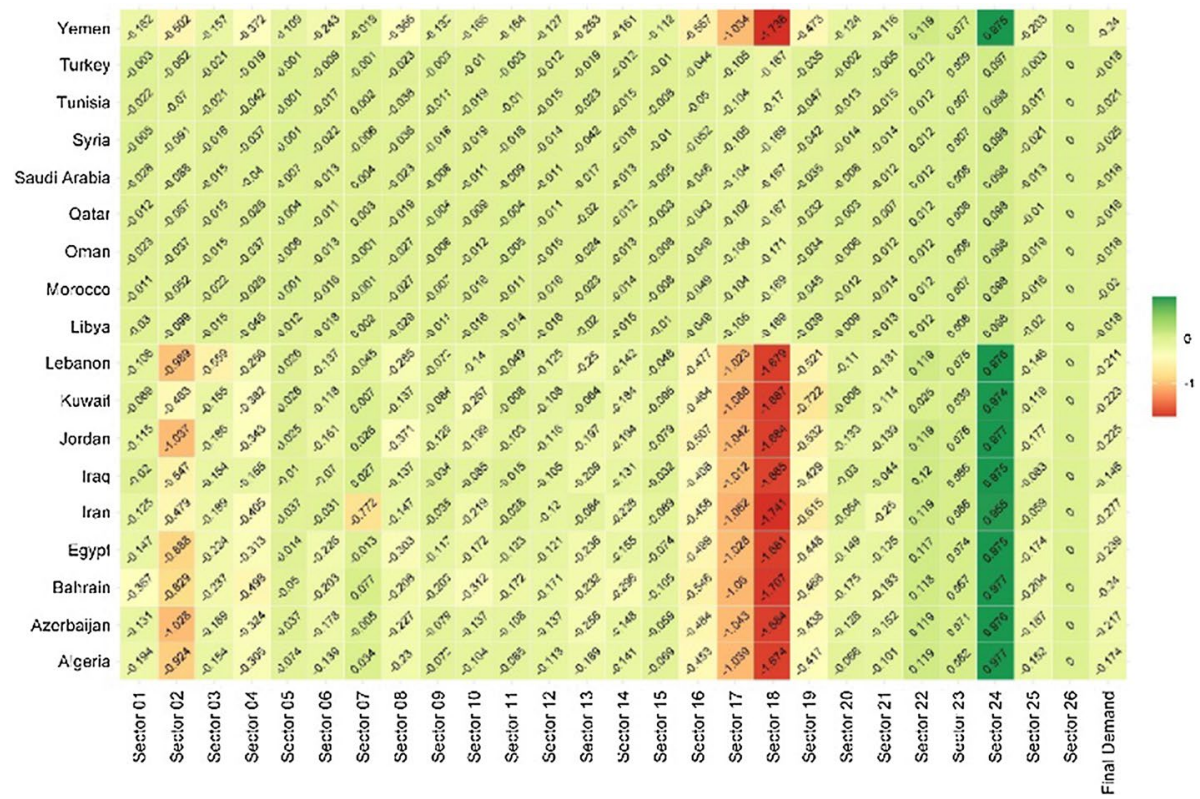

Fig. 4 Changes GHG emissions in each sector based on scenario 3. Source: Authors' calculations

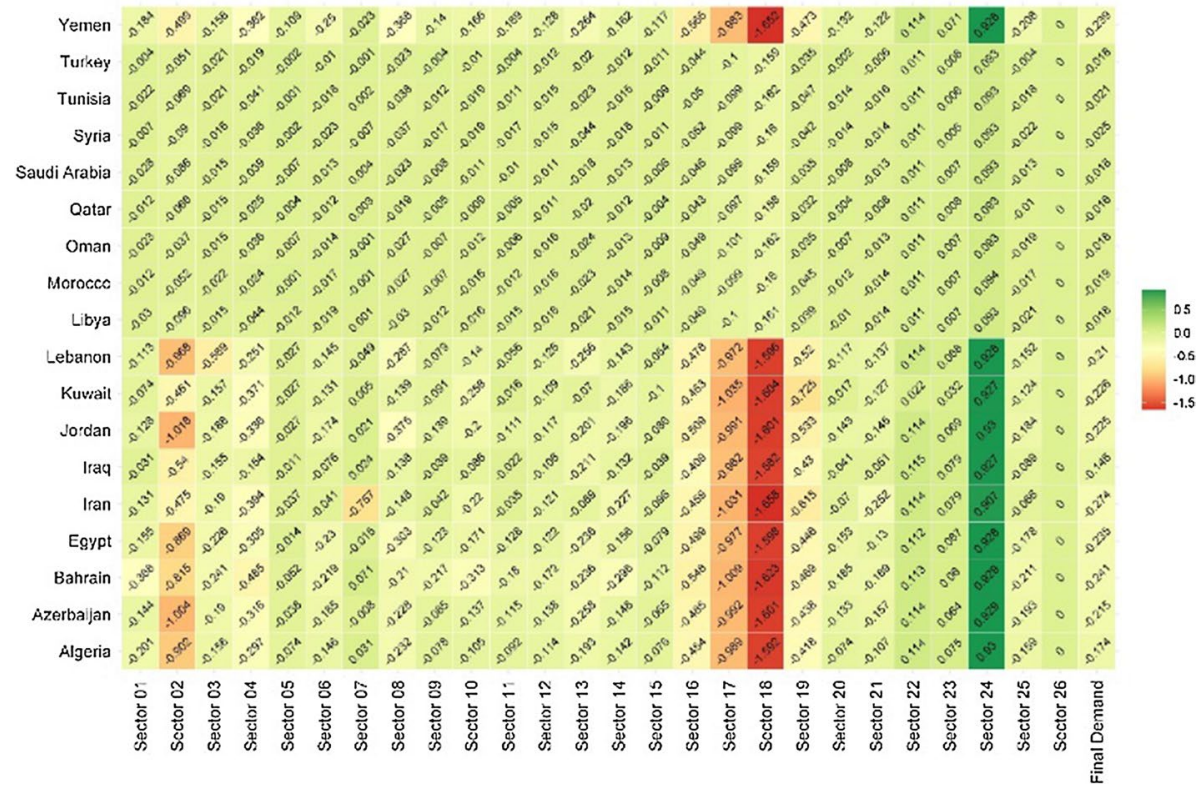

Fig. 5 Changes GHG emissions in each sector based on scenario 4. Source: Authors' calculations 


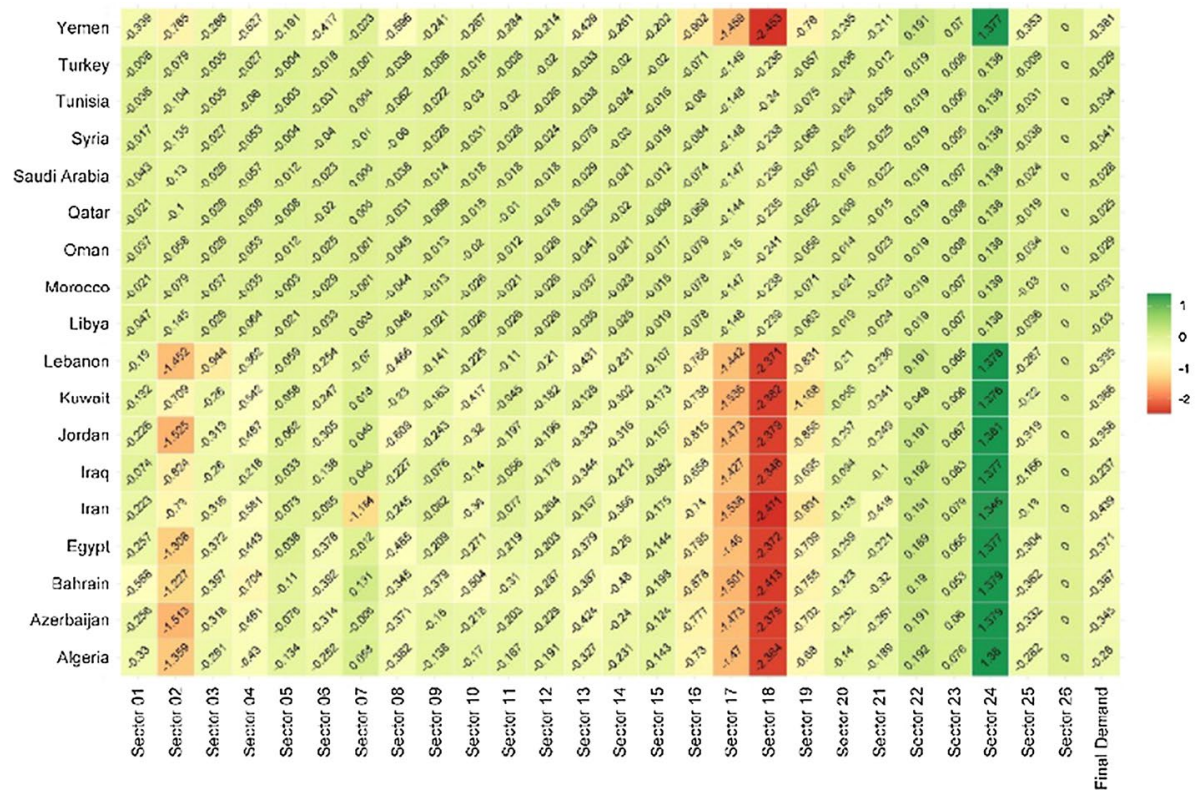

Fig. 6 Changes GHG emissions in each sector based on scenario 5. Source: Authors' calculations

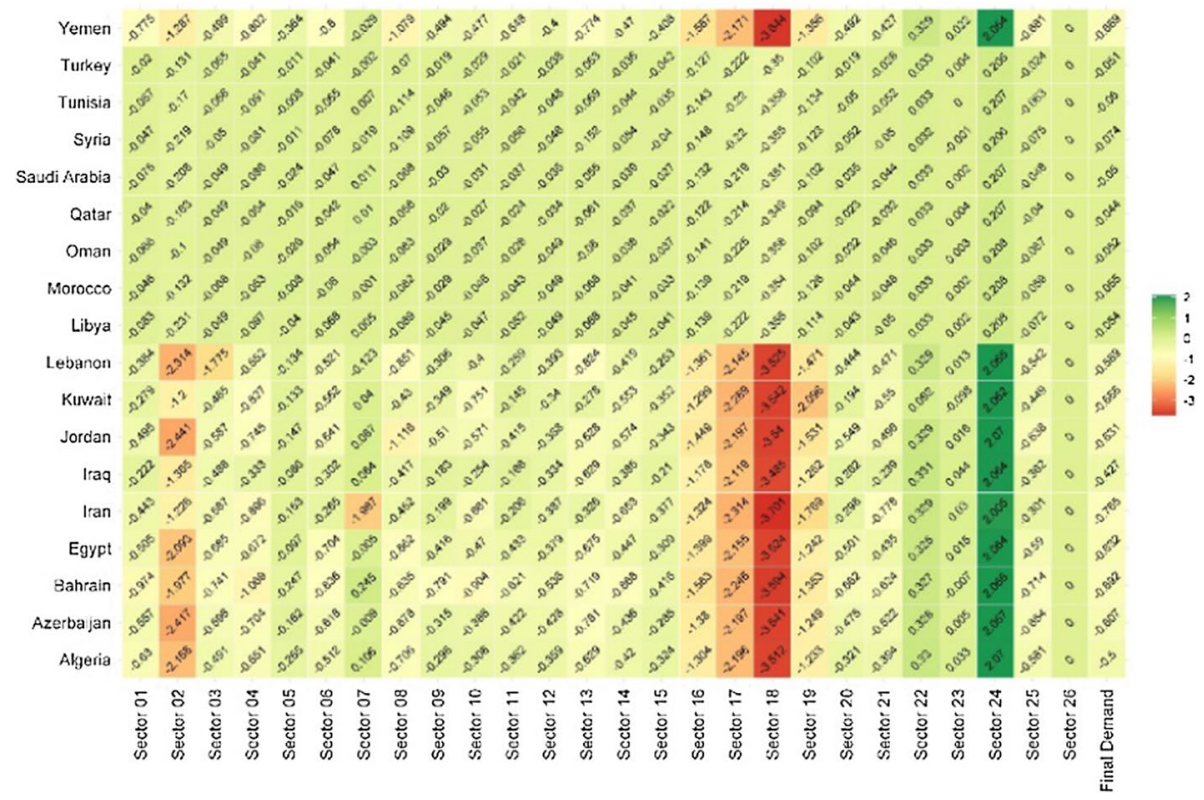

Fig. 7 Changes GHG emissions in each sector based on scenario 6. Source: Authors' calculations 


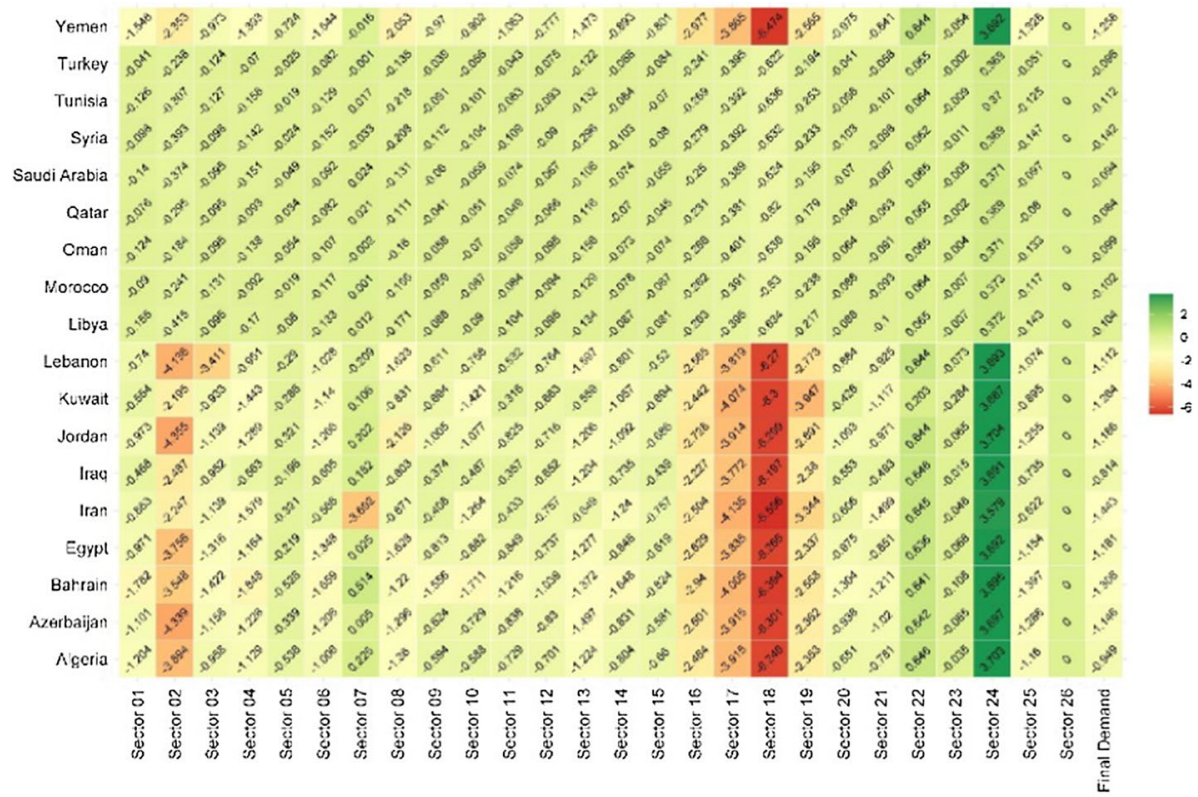

Fig. 8 Changes GHG emissions in each sector based on scenario 7. Source: Authors' calculations

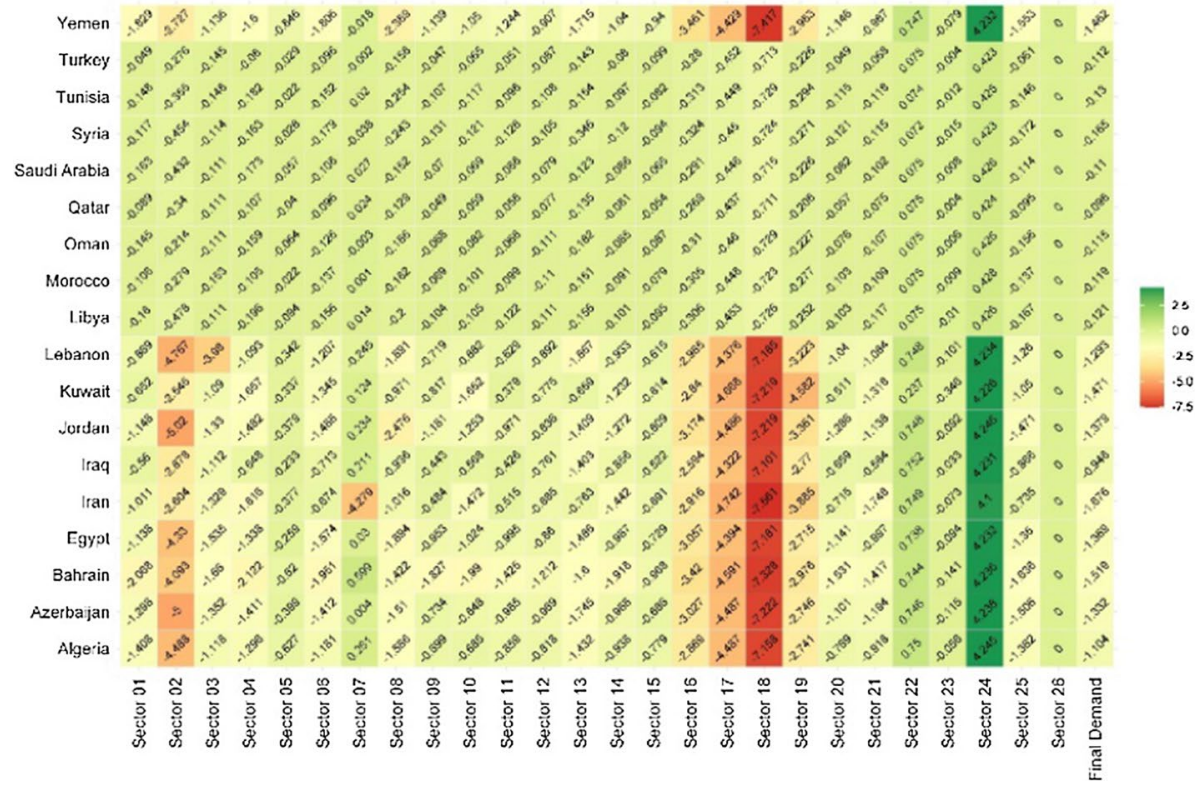

Fig. 9 Changes GHG emissions in each sector based on scenario 8. Source: Authors' calculations 


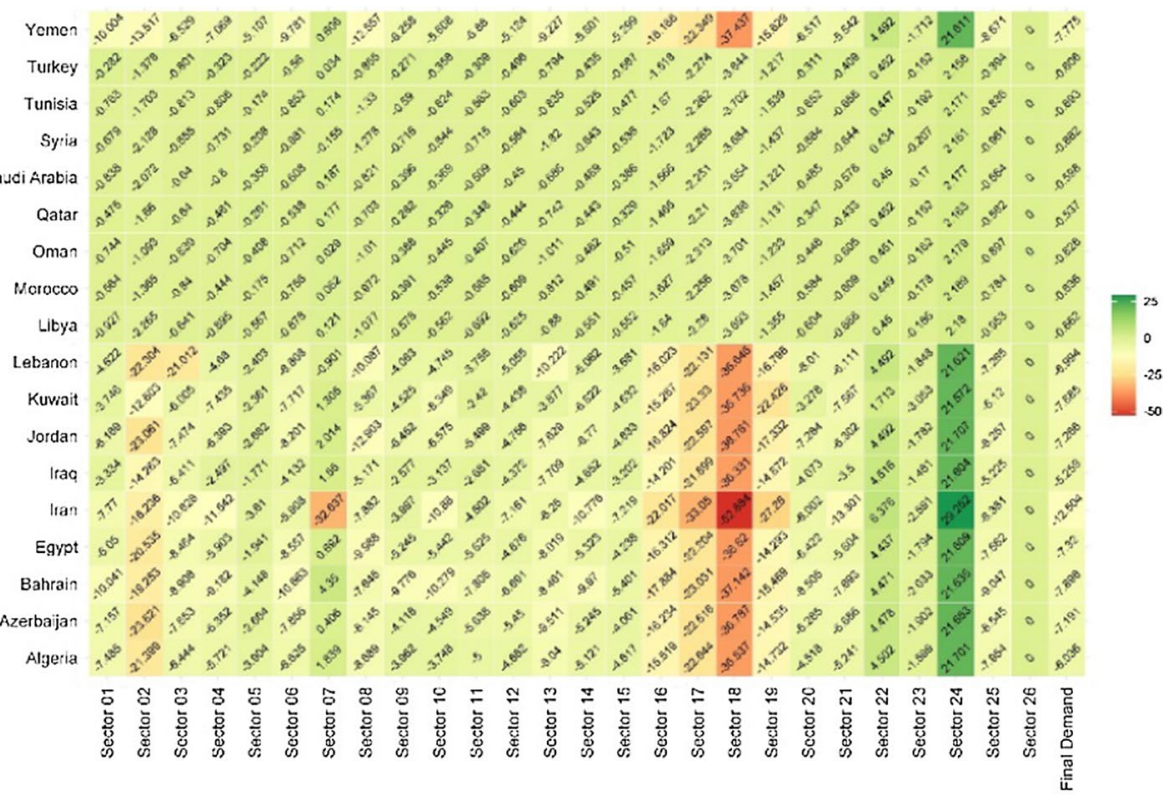

Fig. 10 Changes GHG emissions in each sector based on scenario 9. Source: Authors' calculations

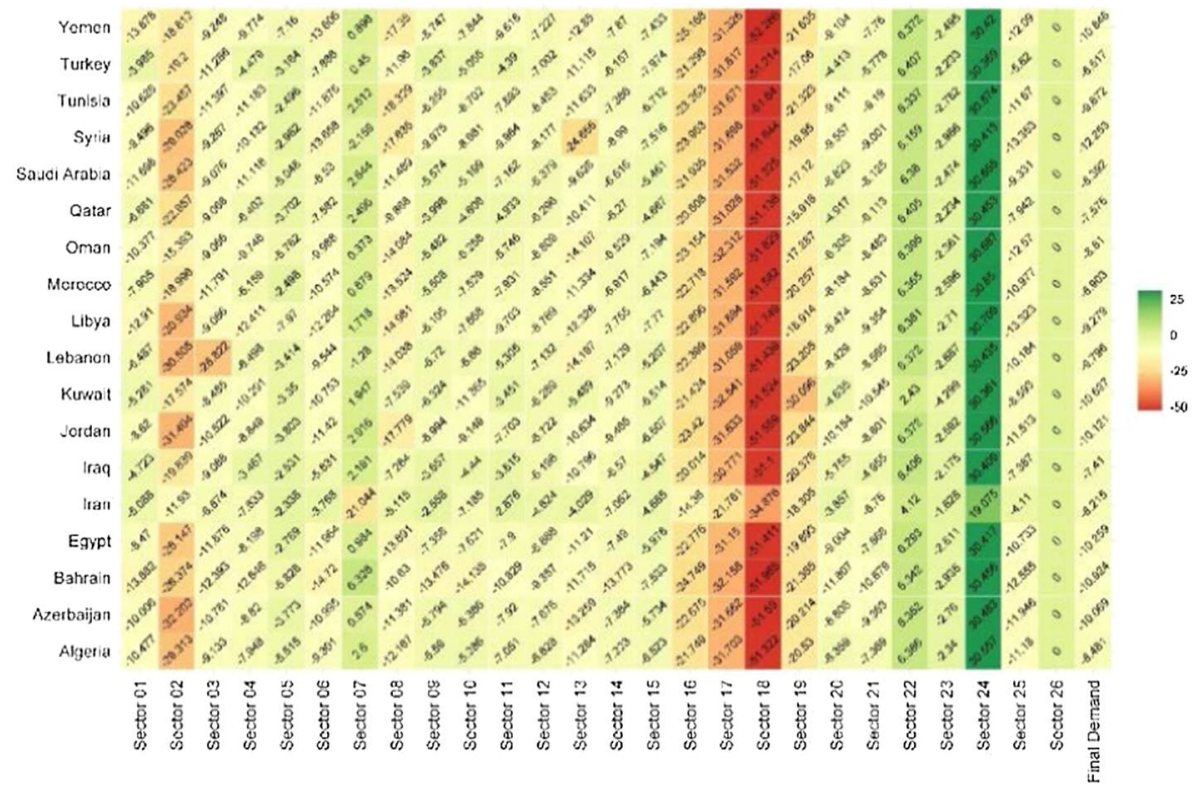

Fig. 11 Changes GHG emissions in each sector based on scenario 10. Source: Authors' calculations 


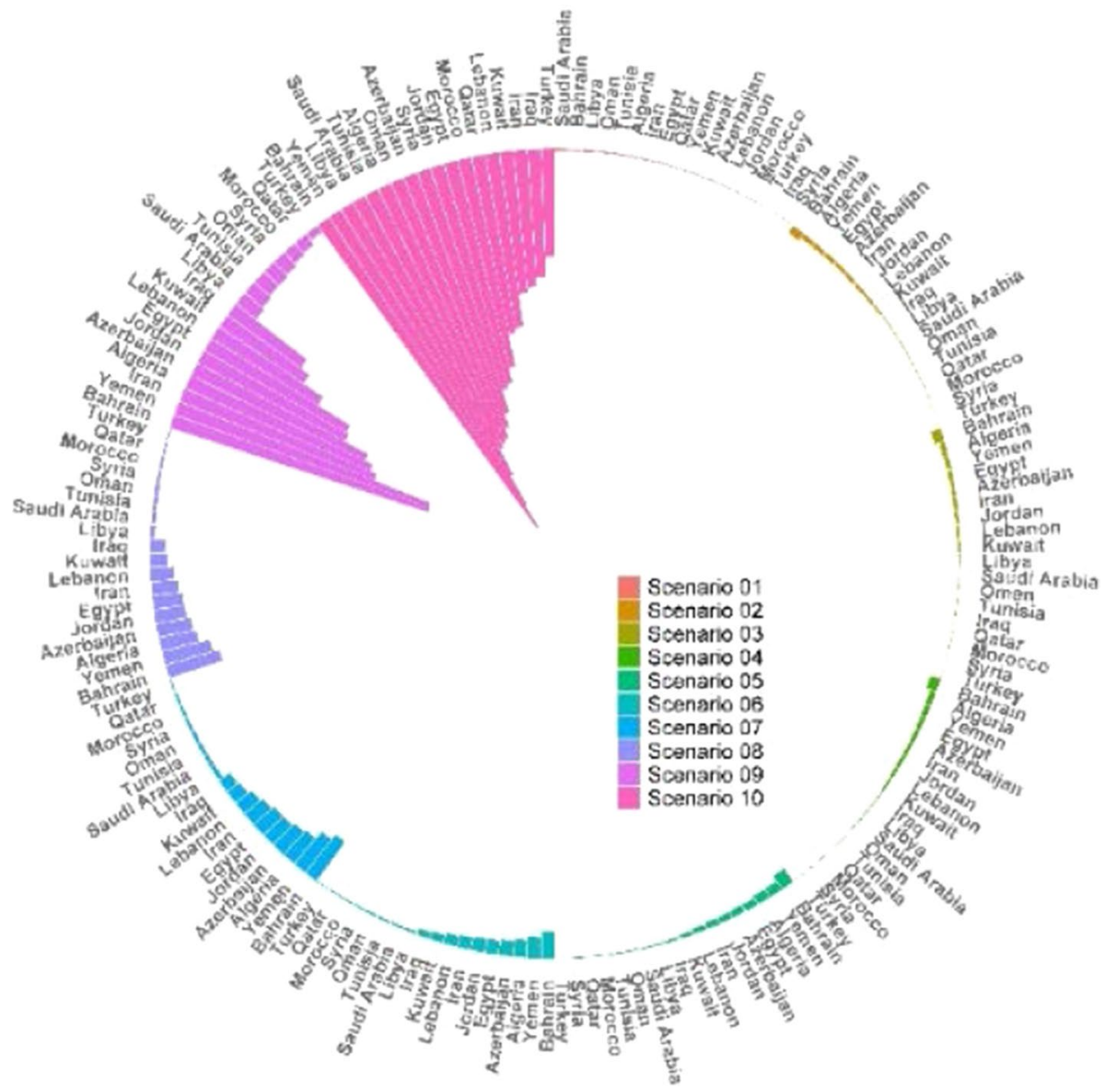

Fig. 12 GHG emission in sector 1. Source: Authors' calculations

\subsection{Discussion}

Regarding the economic shocks resulting from COVID-19 pandemic and in the framework of input-output modelling, and considering the lack of change in production technology in countries affected by the disease, its effects on each of the production and service activities of economies were measured, besides in ten scenarios the trend of changes in greenhouse gas emissions was investigated in 18 countries in the MENA region.

Thus, the trend of changes in greenhouse gas emissions in these 18 countries under various conditions of COVID-19 pandemic that will occur in the future can be summarized as follows: If the first scenario (rapid and complete control of disease) occurs, we will see a tiny amount of reduction in gas emissions. Under these circumstances, Iran will have the highest reduction in GHG emissions, and the three countries of Kuwait, Bahrain, and Qatar will see the least changes in the emissions. The most optimistic scenario for this disease in a given period is scenario one. Based on the second scenario (gradual but complete control of the pandemic over a while), Syria and Iran will see the most considerable reduction in greenhouse gas emissions, while the three countries of Oman, Kuwait, and Qatar will see 


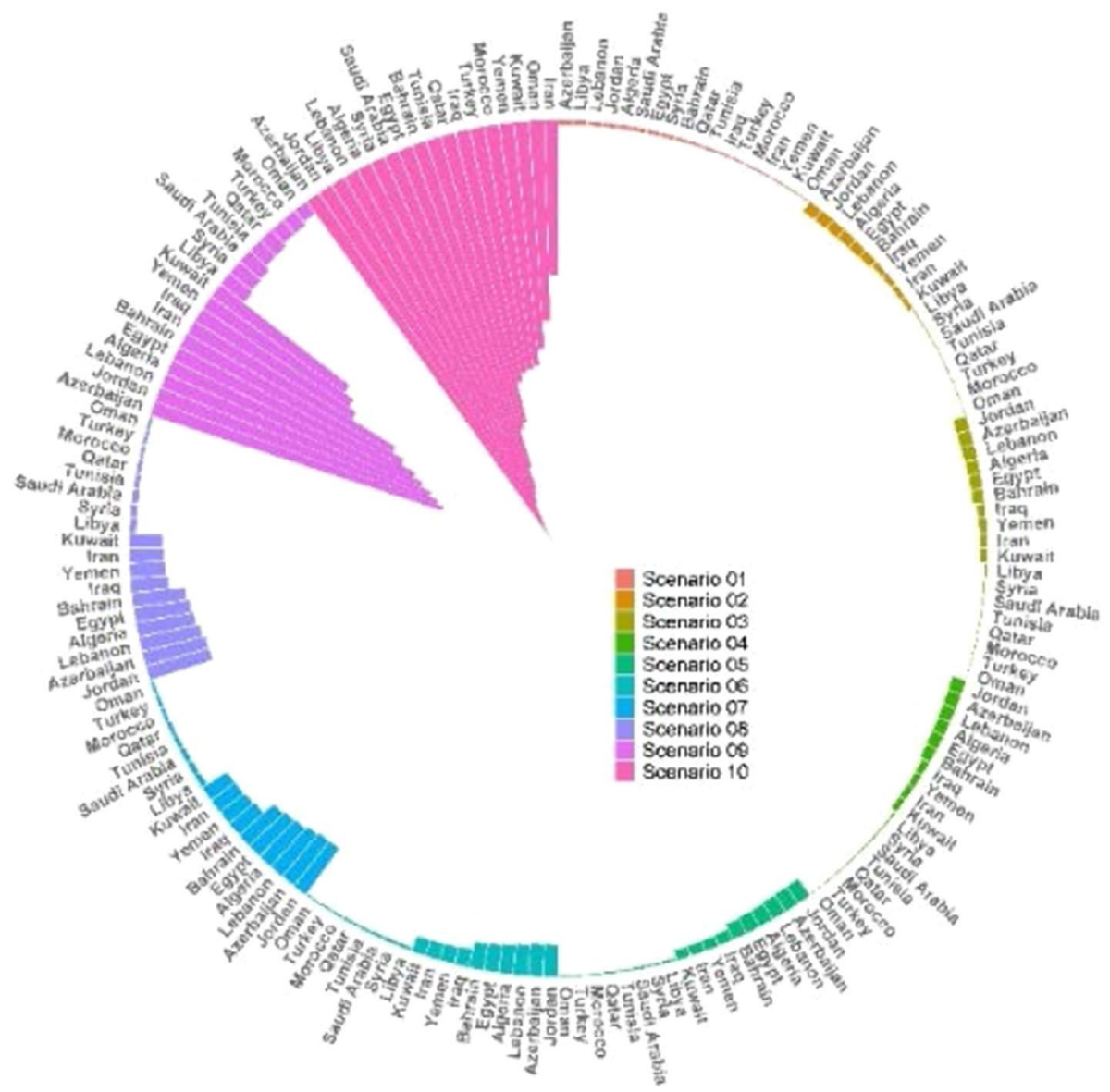

Fig. 13 GHG emission in sector 2. Source: Authors' calculations

the least changes. With the appearance of the third scenario, gradual control of the pandemic by severe reduction in contagion at the end of a period, the emissions of the three countries of Lebanon, Iran and Syria will decrease more than other countries, and Kuwait and Qatar will see the least change.

The results of fourth scenario (i.e., gradual control of the pandemic by a modest reduction in contagion at the end of a period) are very similar to the third scenario, and the situation of countries is not different from each other, and we will only see a further reduction in the emissions. The rate of change in greenhouse gas emissions from the fifth scenario (two identical waves of disease) will be more noticeable than before. Syria, Iran, Lebanon, Jordan, and Azerbaijan will be the leaders to reduce the greenhouse gas emissions, and Turkey, Kuwait, and Qatar have the least change.

The rate of change in greenhouse gas emissions from the fifth scenario (two identical waves of disease) will be more noticeable than before. Syria, Iran, Lebanon, Jordan, and Azerbaijan will be the leaders in reducing greenhouse gas emissions, with Turkey, Kuwait, and Qatar having the least change. If the sixth scenario, i.e., two dissimilar waves of disease, transpires, the reduction of greenhouse gas emissions in Syria will be significantly 


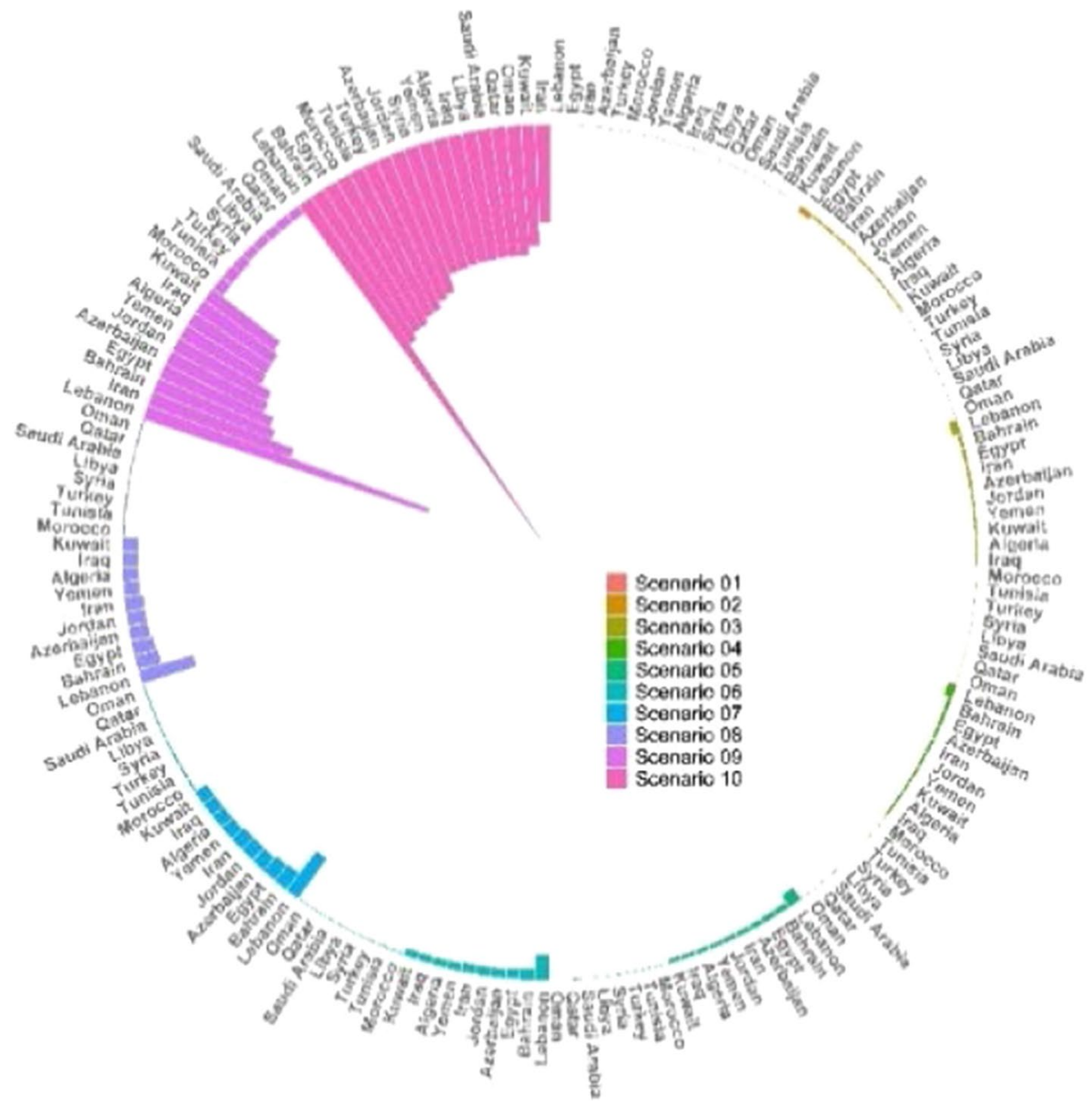

Fig. 14 GHG emission in sector 3. Source: Authors' calculations

more significant than the others, followed by Iran, Lebanon, Jordan, and Azerbaijan. Although Saudi Arabia was usually in the middle of the region (neither a sharp decline in emissions nor the slightest decrease), but from the sixth scenario onwards, it is one of the countries that will see the least change in greenhouse gas emissions.

The seventh scenario (a sustained wave of disease and a sensitive declining trend at the end of a period) is almost similar to the sixth scenario, except that greenhouse gas emissions decreased by one more per cent on average. In scenario eight (a sustained wave of disease with a mild declining trend at the end of a period), the only country that will see very little change in reducing greenhouse gas emissions is Qatar. In contrast, Syria is witnessing a significant reduction in gas emissions. The other 16 countries, namely Iran, Lebanon, Jordan, Azerbaijan, Yemen, Tunisia, Libya, Iraq, Egypt, Morocco, Algeria, Bahrain, Oman, Turkey, Saudi Arabia, Kuwait, will see a decrease in gas emissions.

The ninth and tenth scenarios reflect extreme quarantine circumstances, and the emission statistics in these two situations are completely different from the other scenarios owing to the severity of the limitations. In the ninth scenario (the pandemic worsens step 


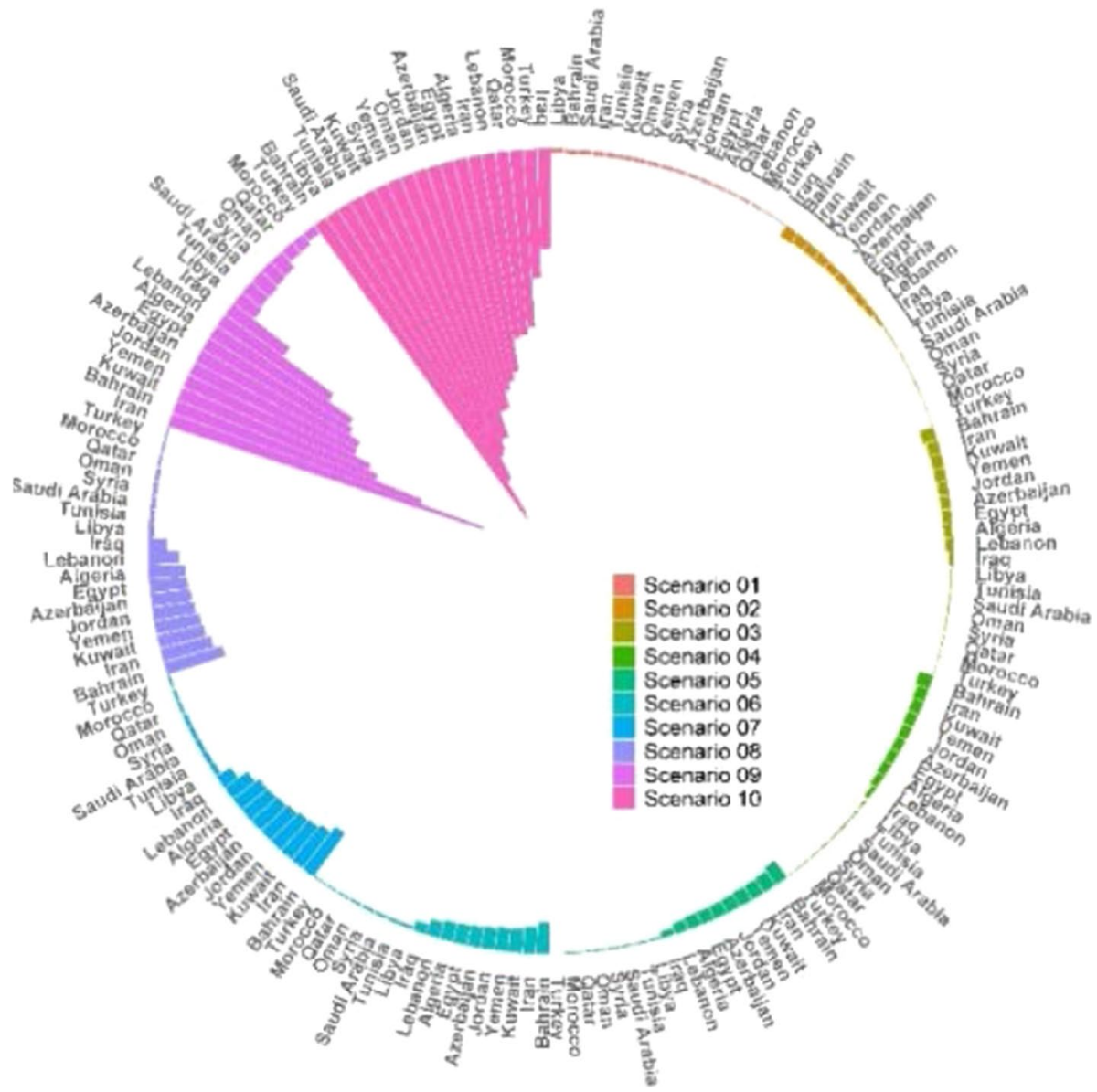

Fig. 15 GHG emission in sector 4. Source: Authors' calculations

by step without subsiding over a while), Iran and Syria are two countries that will face a significant difference in reducing greenhouse gas emissions. After these two, the five countries of Lebanon, Jordan, Azerbaijan, Yemen, and Libya are witnessing relatively large greenhouse gas emissions reductions. Nine countries, Tunisia, Iraq, Egypt, Morocco, Algeria, Oman, Turkey, Saudi Arabia, Bahrain, are in the middle. Moreover, at the end of the list are Kuwait and Qatar.

The tenth scenario (explosive intensification of the pandemic without the wave subsiding over a while), which can be called the most pessimistic scenario, like scenario 9, changes all countries in the region in greenhouse gas emissions. Thus, these reductions will be due to the restrictions imposed and not changes in production technology. However, the tenth scenario for 17 of the 18 countries achieves the highest reduction in greenhouse gas emissions, in contrast to Iran, which has the highest reduction in the ninth scenario.

As it is clear from the comparison of Figs. 11, 12, 13, 14, 15, 16, 17, 18, 19, 20, 21, 22, $23,24,25,26,27,28,29,30,31,32,33,34,35,36,37$, the most massive reduction in pollution in these countries was related to the reduction in the activities of the sectors "Hotels and Restaurants," "Retail Trade" and "Fishing." 


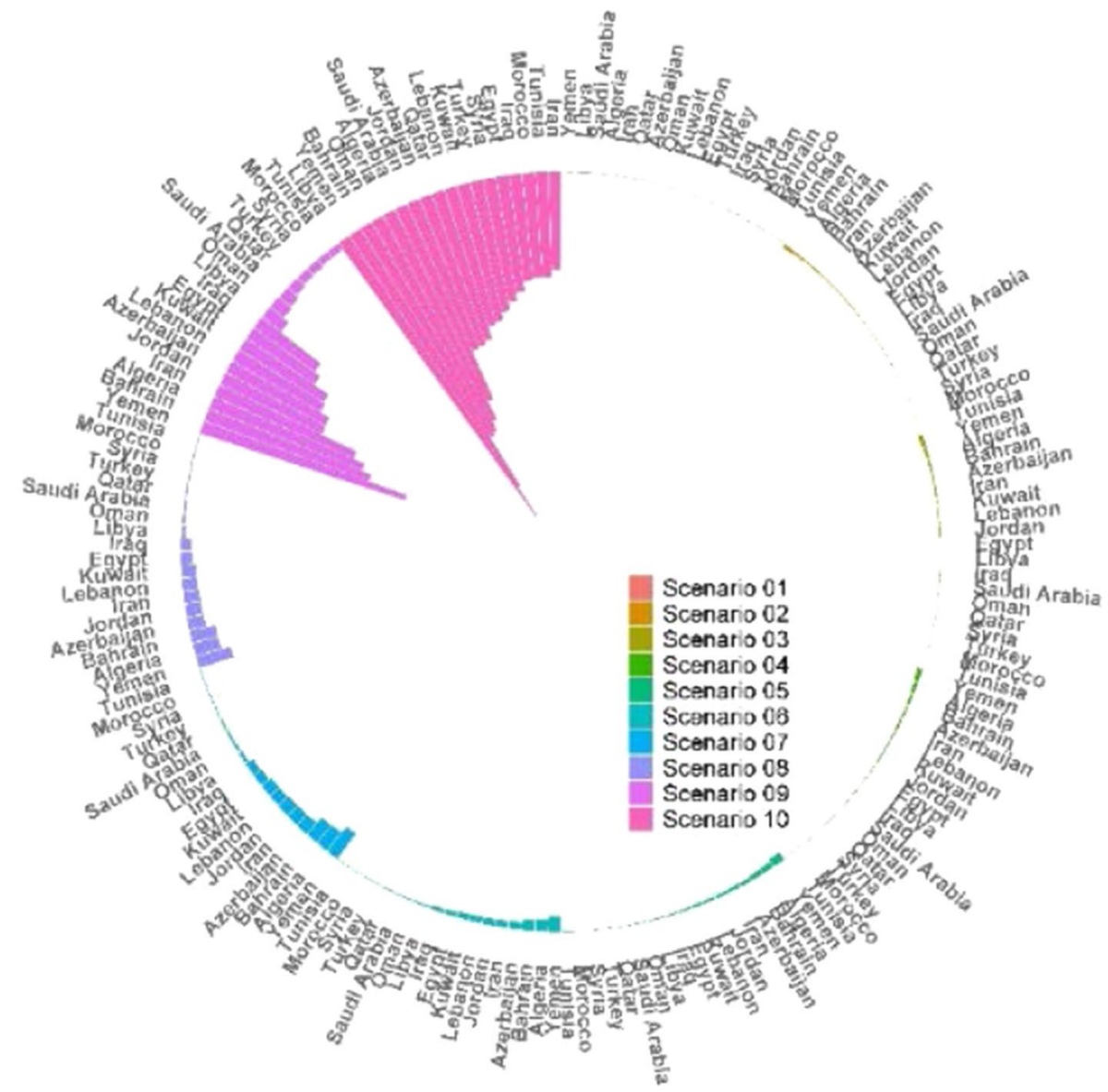

Fig. 16 GHG emission in sector 5. Source: Authors' calculations

\section{Conclusion and implications}

COVID-19 pandemic began deep in China's Hebei Province and is spreading rapidly. The high rate of the virus has now been reported from East Asia to the Middle East, Europe, and the Americas, and in several countries, the death rate has surpassed that of China. Coronavirus 2019, or COVID-19, also known as nCoV acute respiratory disease 2019, is an infectious disease caused by the new coronavirus, a virus very similar to SARS. The economic consequences of outbreak could include the United States, the Eurozone, the Middle East, and the Far East, and as health policies are adopted, rulers are thinking about the economic consequences.

By the exponential spread of this virus in different communities, strict rules of banning traveling, restrictions on trade and travel, quarantine of cities, etc., have also increased in countries and raised economists' concerns. Given the totality of restrictions imposed, the range and duration of the virus's economic effect are unknown. Like a healthy person who suffers from seasonal flu, there is short-term and sectional discomfort, but he quickly returns to the previous state of health so that this crisis can have a V-shaped behaviour. 


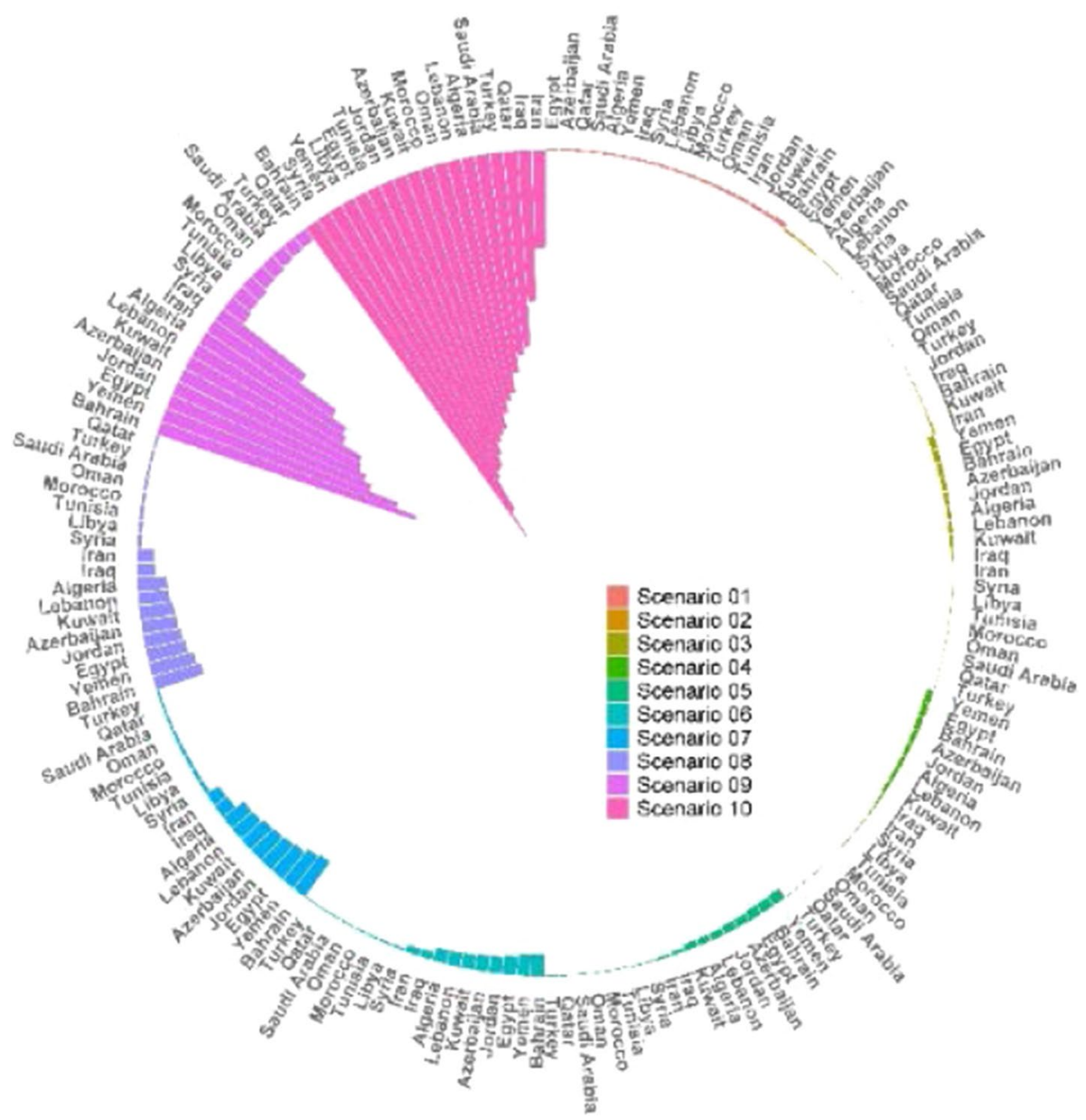

Fig. 17 GHG emission in sector 6. Source: Authors' calculations

However, there is no guarantee that the disease's behaviour and its effect on the economy will be like this. Another point is that now is the time to say that COVID-19 is just China's problem. Although some still think that COVID-19 could be a short-lived crisis, this does not seem to be the case. The disease is spreading in many countries around the world. Nevertheless, the note is that when there is high uncertainty about disease behaviour and outcomes, this economic shock can cause long-term adverse outcomes and leave deep scars, even more profound than other diseases and the pandemics that have occurred so far.

Diseases, pandemics, and pandemics have exogenous shock nature in the economy since their entering mechanism to economic interactions, and relations is developing from external factors. Hence, the channels of this phenomenon to the economy should be identified. In this type of modelling, the economic effects and loss are modelled in the short term because experiences have shown that the discovery of vaccines and drugs for diseases will not be long-term. Hence, it can be considered that the production technology will not change during this period, and input-output tables of recent years can be used. The two main channels of a shock to the economy are affected by supply and demand. Reducing 


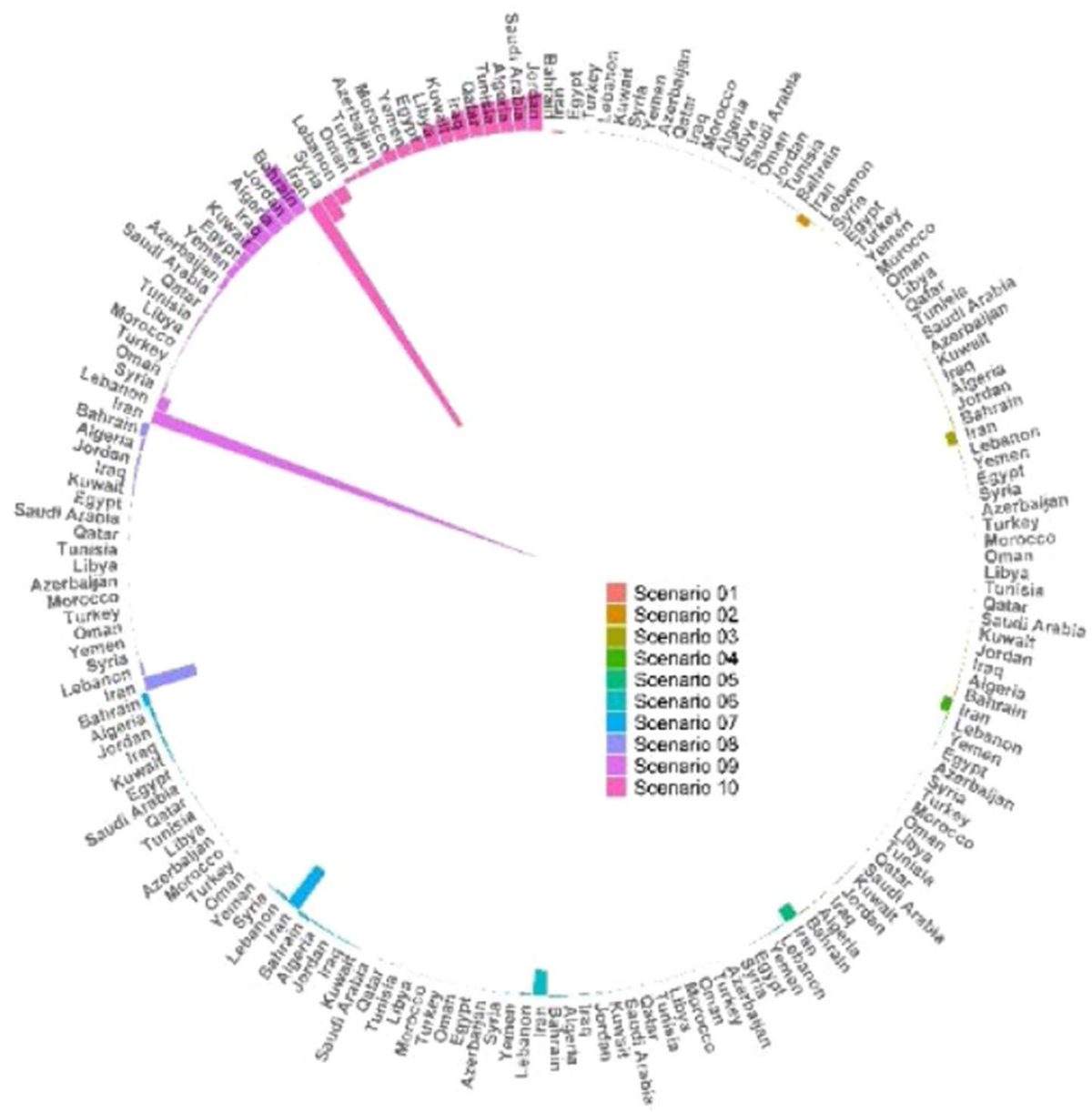

Fig. 18 GHG emission in sector 7. Source: Authors' calculations

firms' activity, staffing of economic activities, and the demand of the private and public sectors will finally enter the global economy's supply chain and affect all countries, even if they are immune to this disease.

Regarding the economic shocks resulting from the COVID-19 pandemic and in the framework of input-output modelling, and considering the lack of change in production technology in countries affected by the disease, its effects on each of the production and service activities of economies were measured, besides in ten scenarios the trend of changes in greenhouse gas emissions was investigated in 18 countries in the MENA region.

In general, the result indicated the significant impact of COVID-19 restrictions on the emission of greenhouse gas from all the sectors, particularly Hotels and Restaurants," 


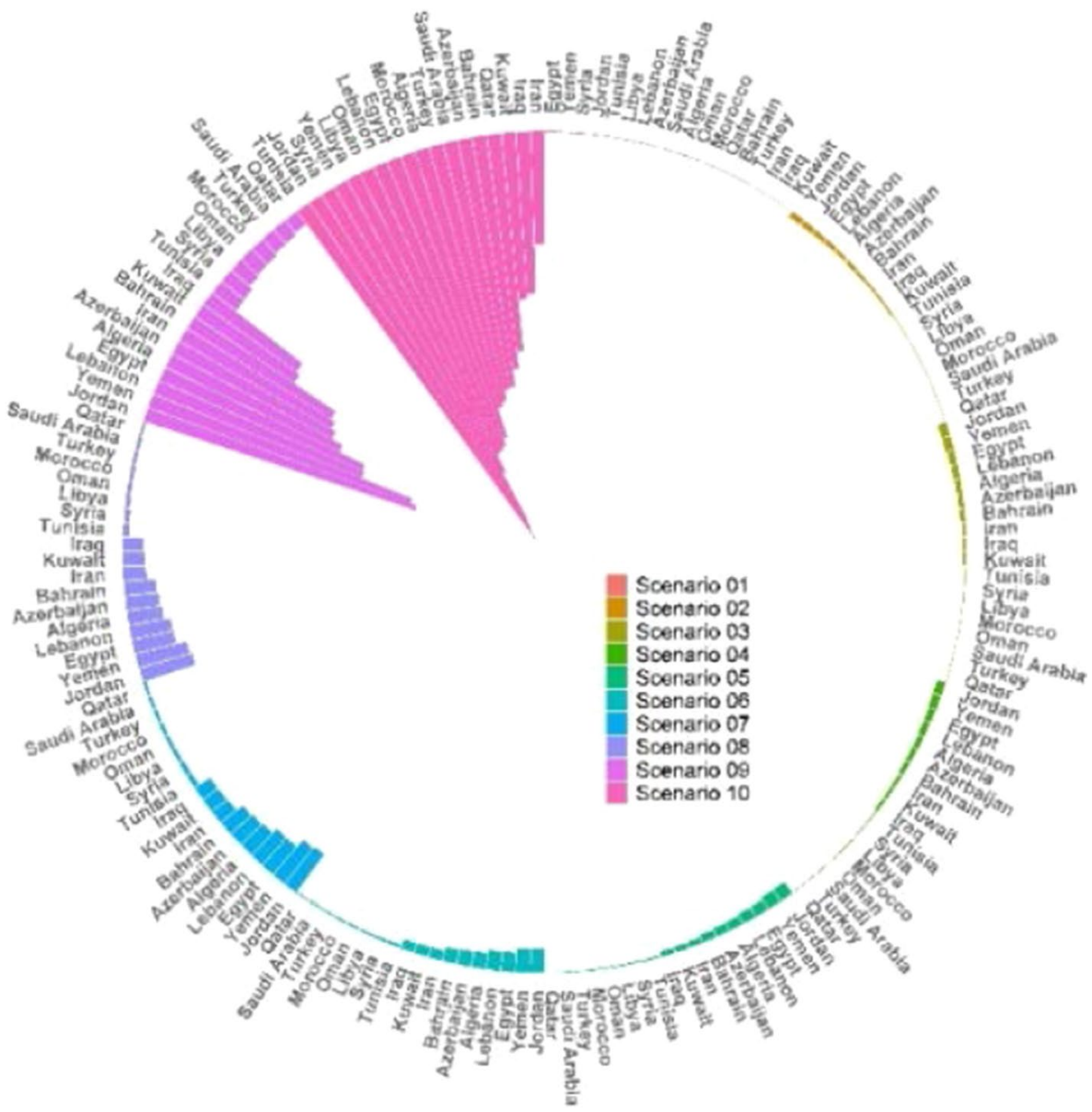

Fig. 19 GHG emission in sector 8. Source: Authors' calculations

"Retail Trade" and "Fishing sectors in every selected Islamic and MENA country. However, there are some exceptions like "Private Households" and "Public Administration," sectors that despite all restrictions, increase their own greenhouse gas emissions, since as quarantine intensifies, the supply of these services increases, and quarantine works in reverse against these two sectors. Besides the four sectors of "Education, Health and Other Services," and "Petroleum, Chemical, and Non-Metallic Mineral Products," and "Textiles and Wearing Apparel," and "Re-export \& Re-import" are indifferent to the restrictions. However, the five sectors that will have the highest emissions reductions are "Hotels and Restaurants," "Retail Trade," "Fishing," "Wholesale Trade," and "Transport," which are ahead of the rest due to quarantine or restrictions on the COVID-19 pandemic.

Future studies can focus on finding the impact of OCID-19 restriction in other countries in other regions around the world using more advanced and comprehensive methods and approaches. 


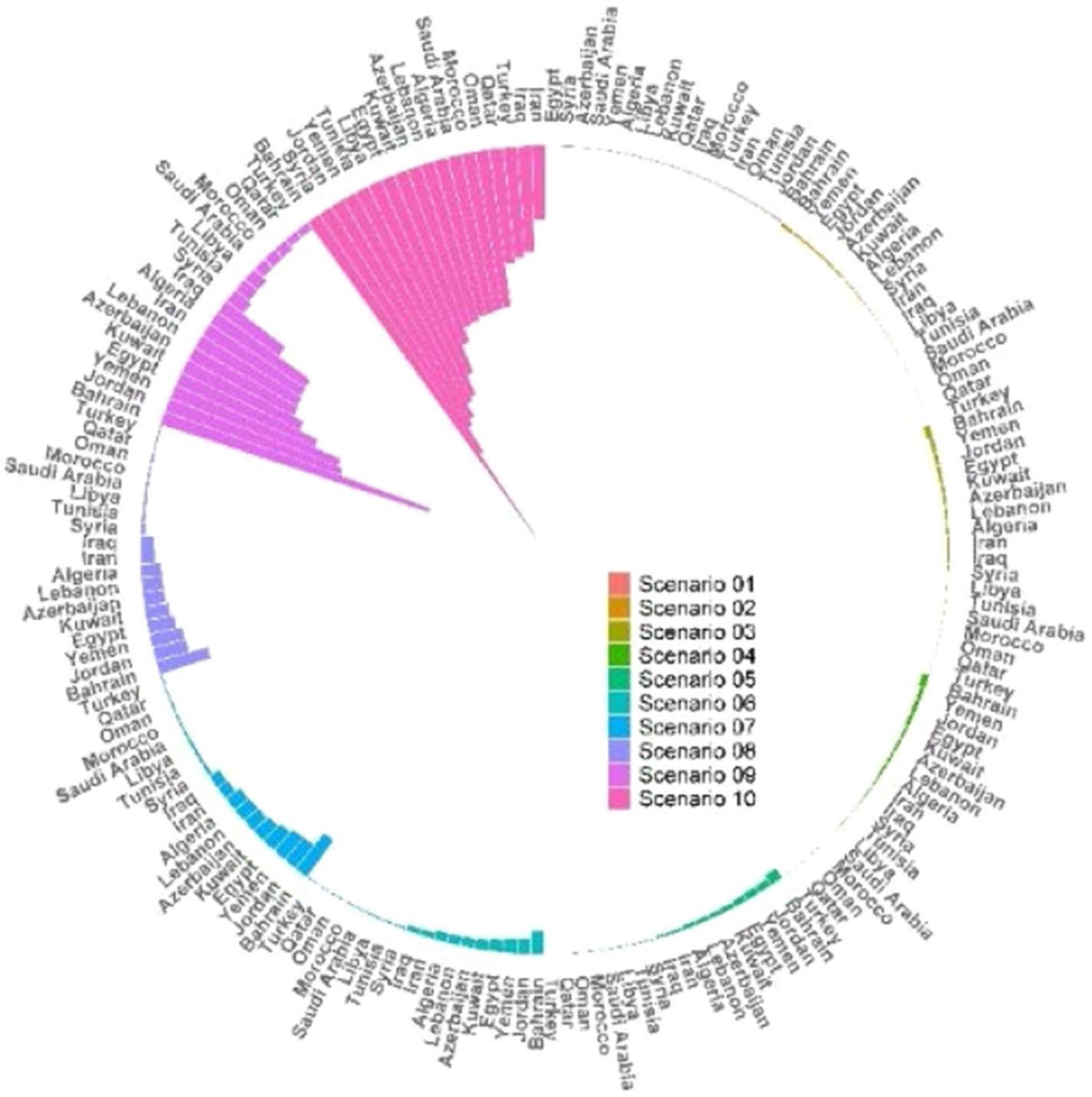

Fig. 20 GHG emission in sector 9. Source: Authors' calculations 


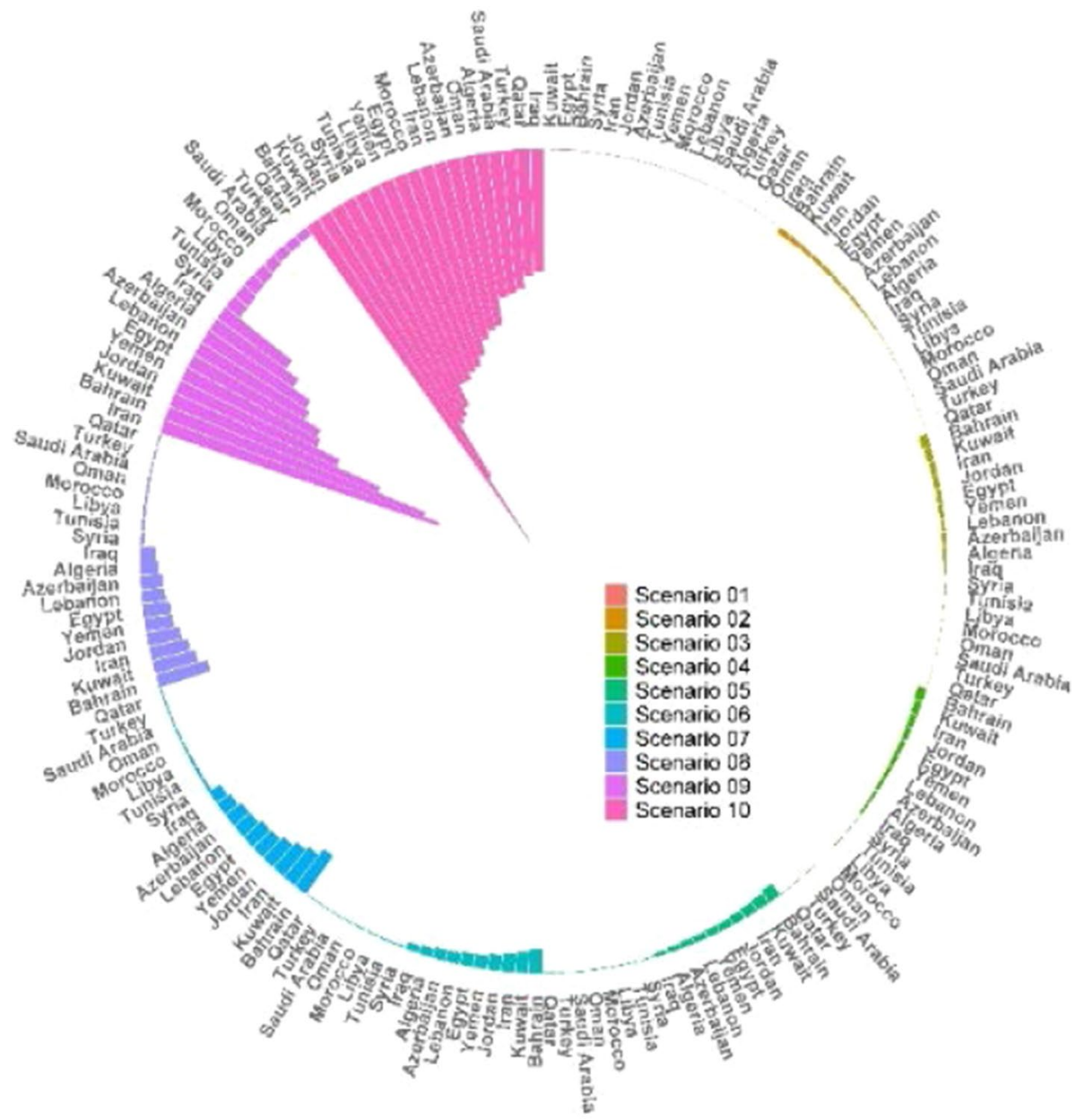

Fig. 21 GHG emission in sector 10. Source: Authors' calculations 


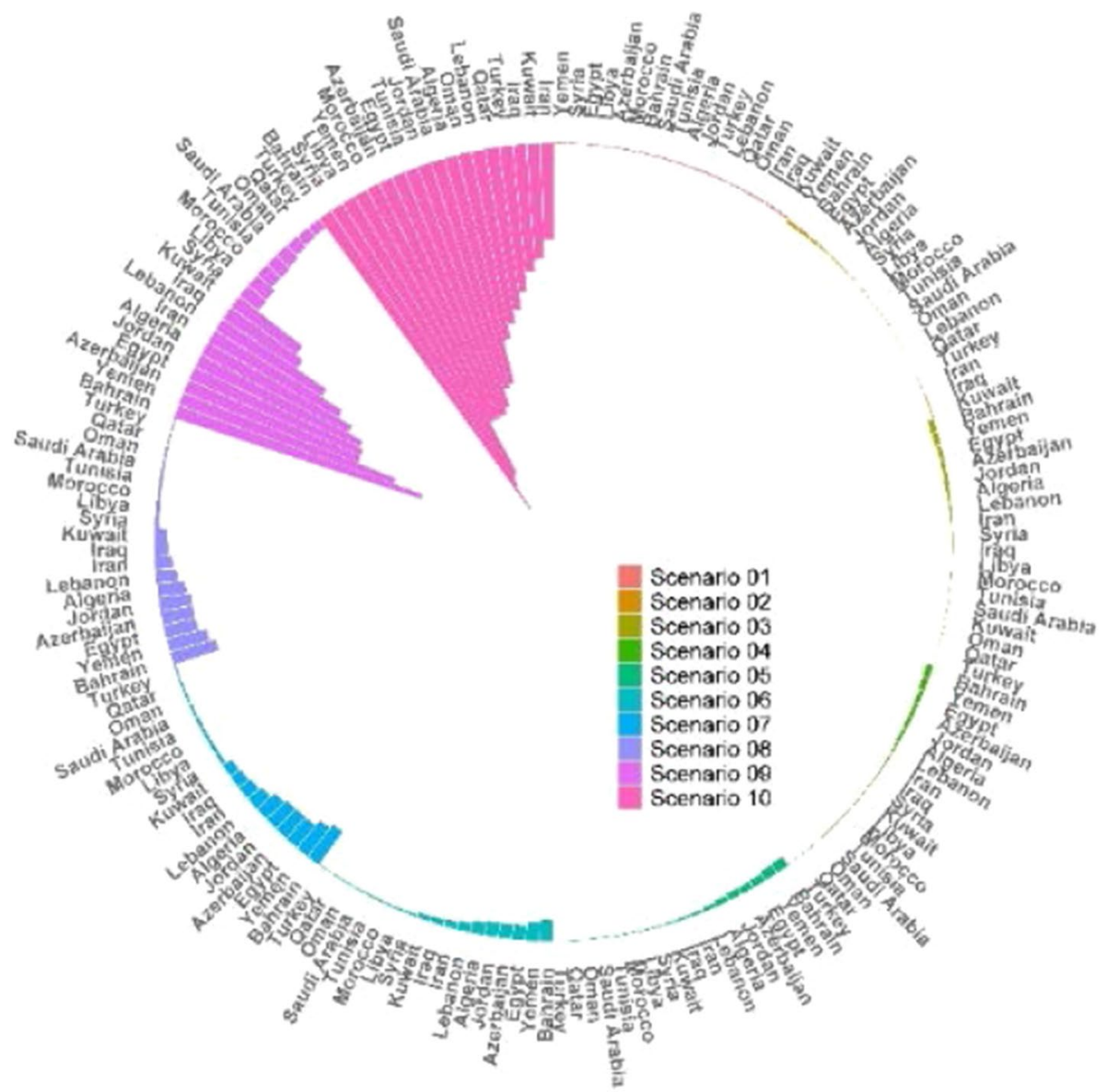

Fig. 22 GHG emission in sector 11. Source: Authors' calculations 


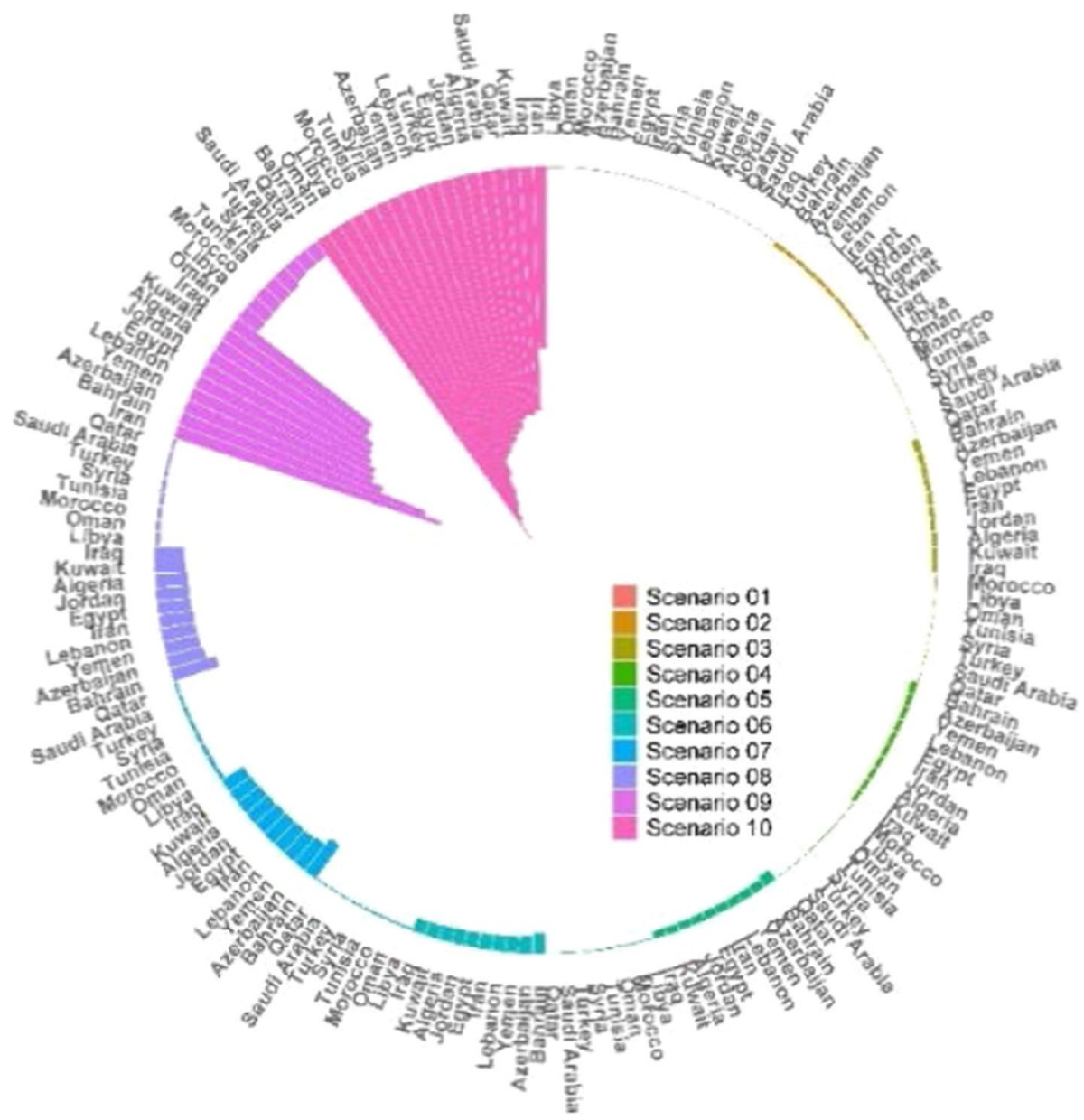

Fig. 23 GHG emission in sector 12. Source: Authors' calculations 


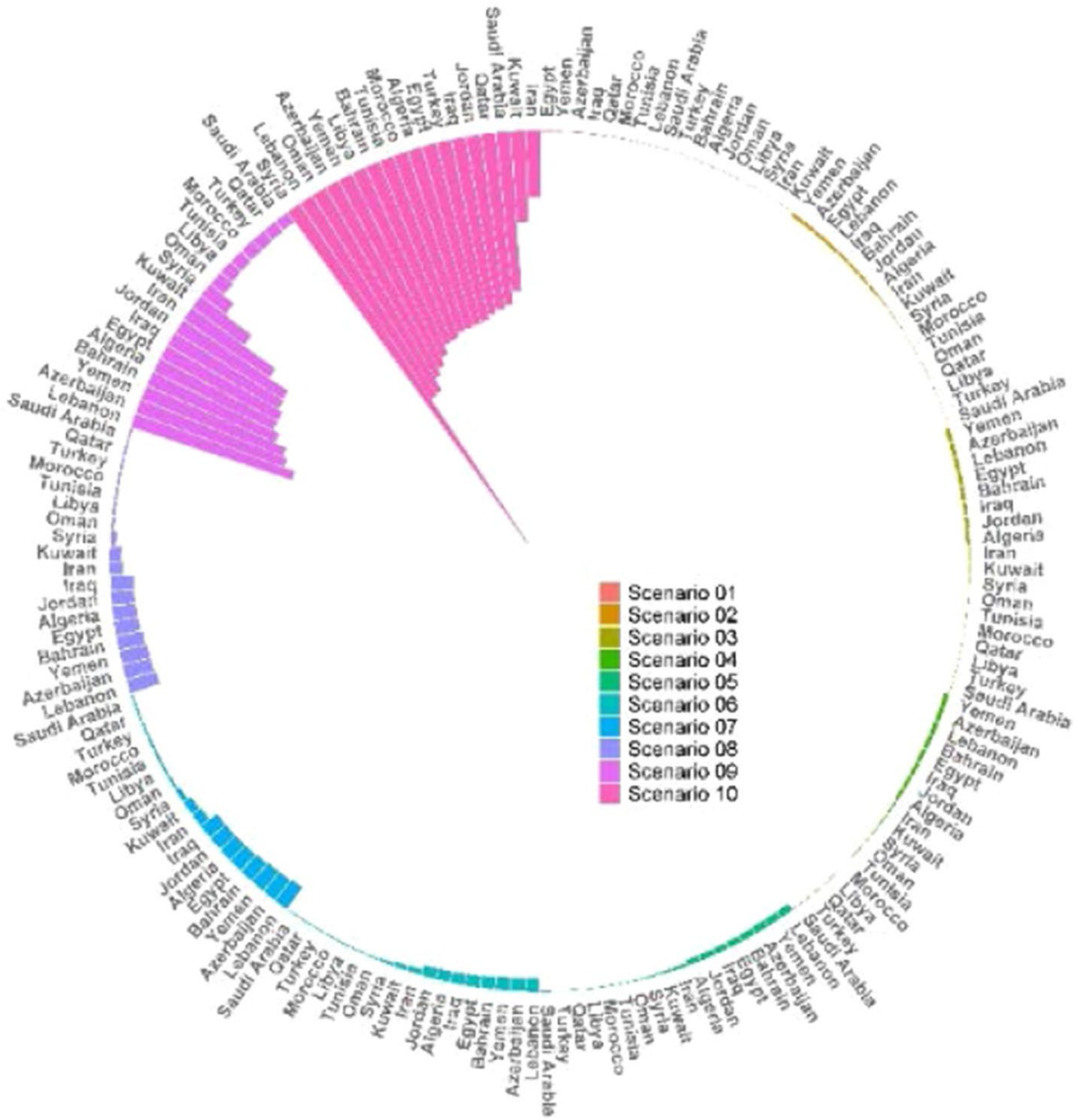

Fig. 24 GHG emission in sector 13. Source: Authors' calculations 


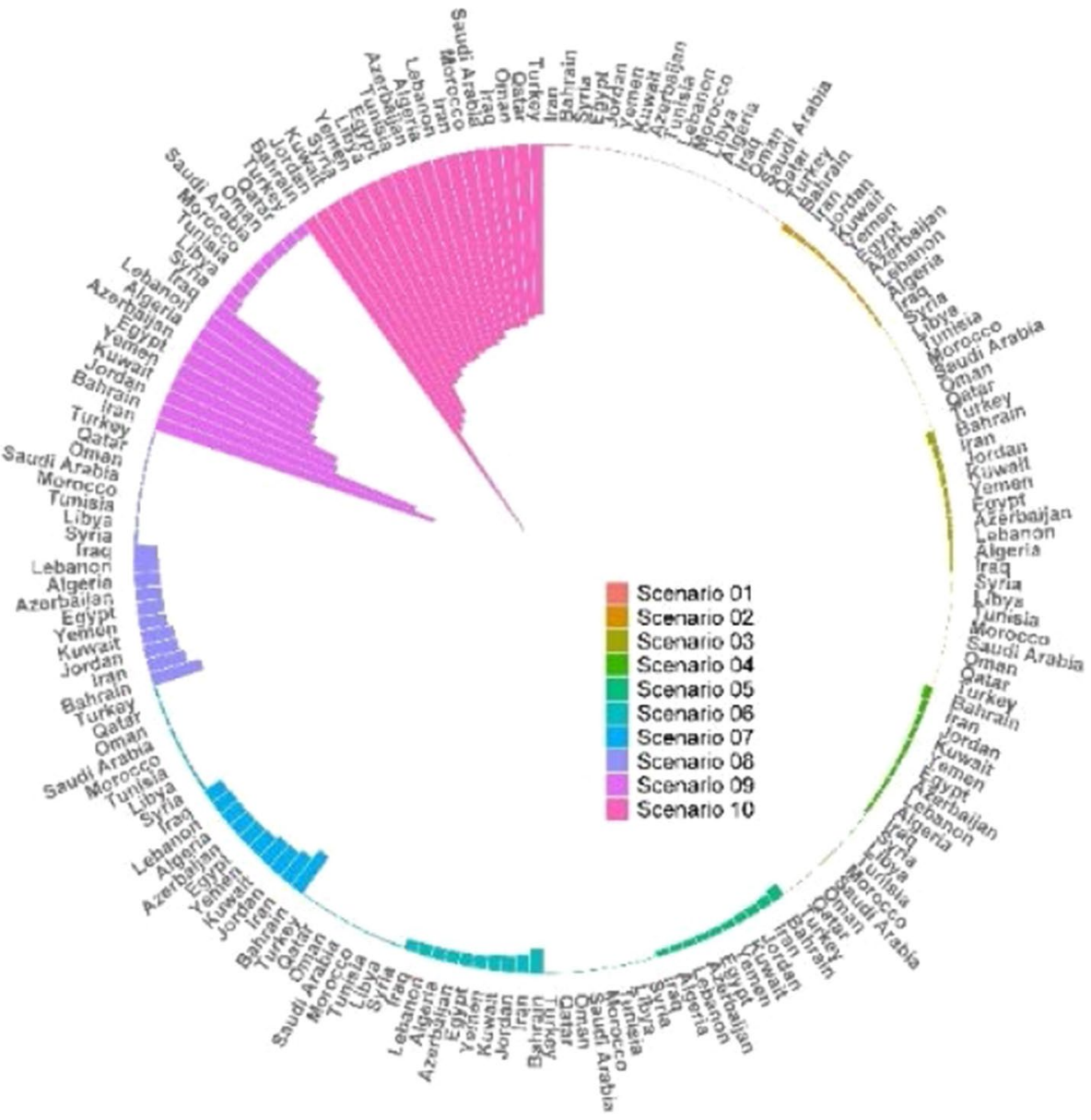

Fig. 25 GHG emission in sector 14. Source: Authors' calculations 


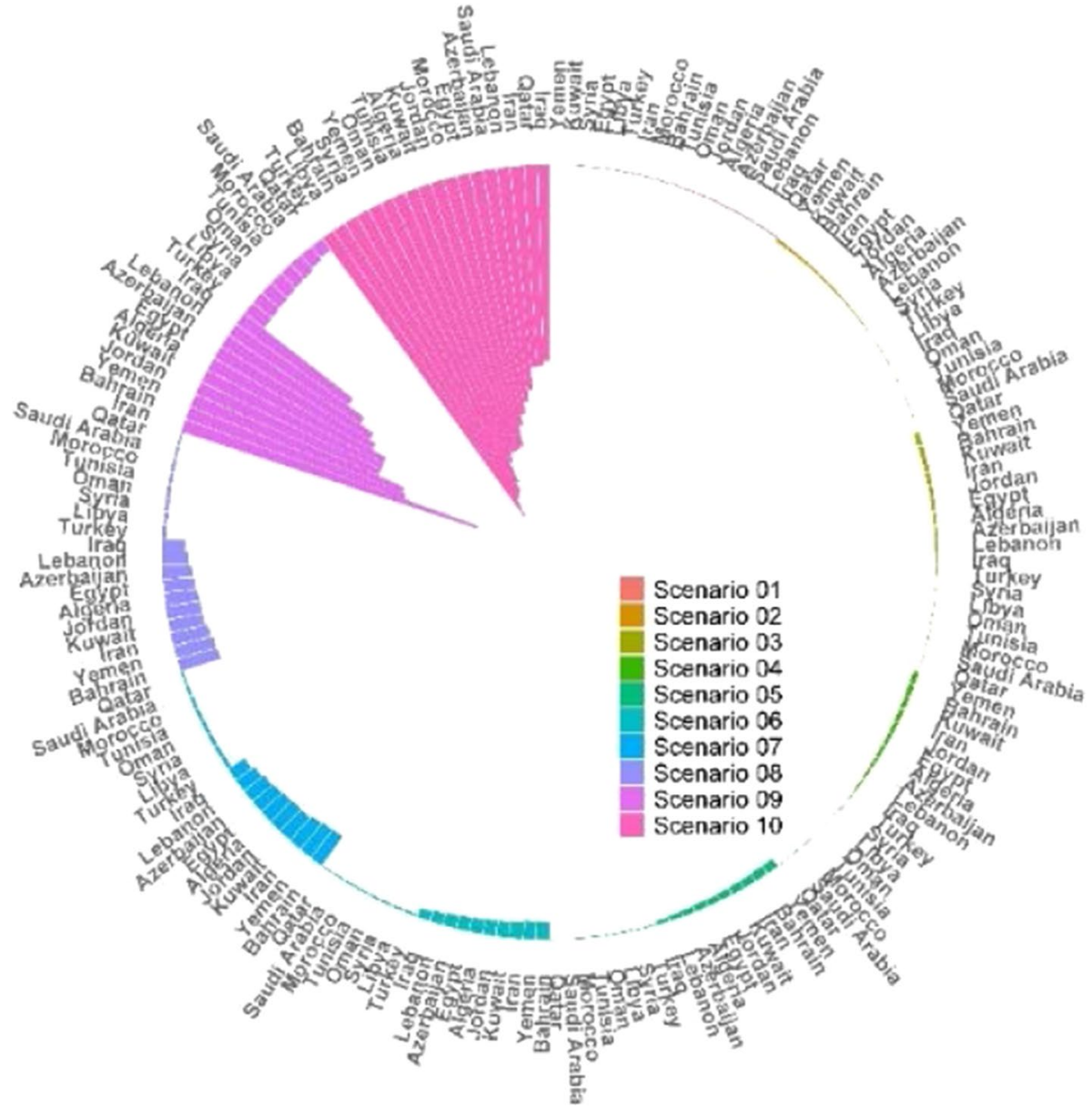

Fig. 26 GHG emission in sector 15. Source: Authors' calculations 


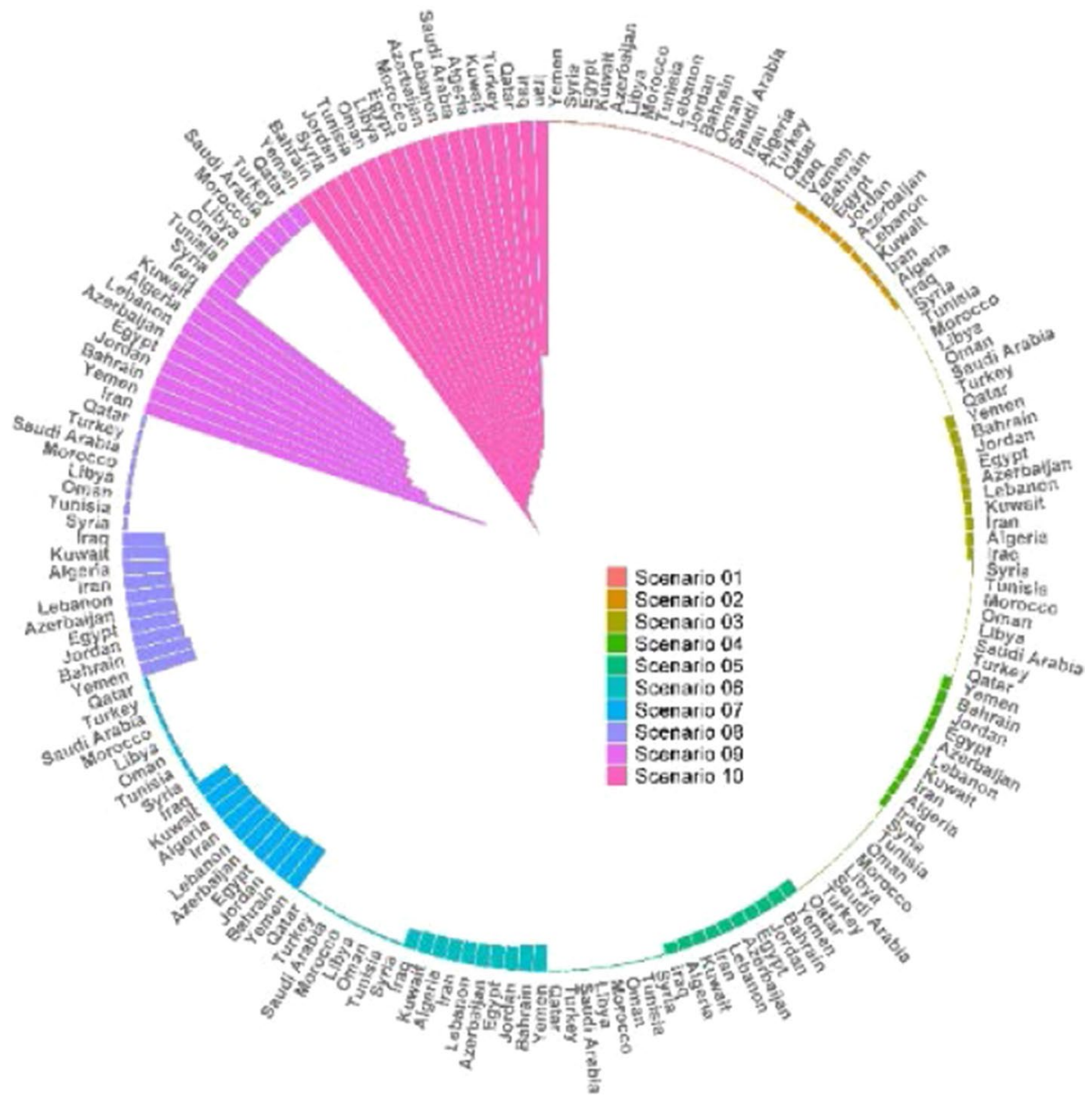

Fig. 27 GHG emission in sector 16. Source: Authors' calculations 


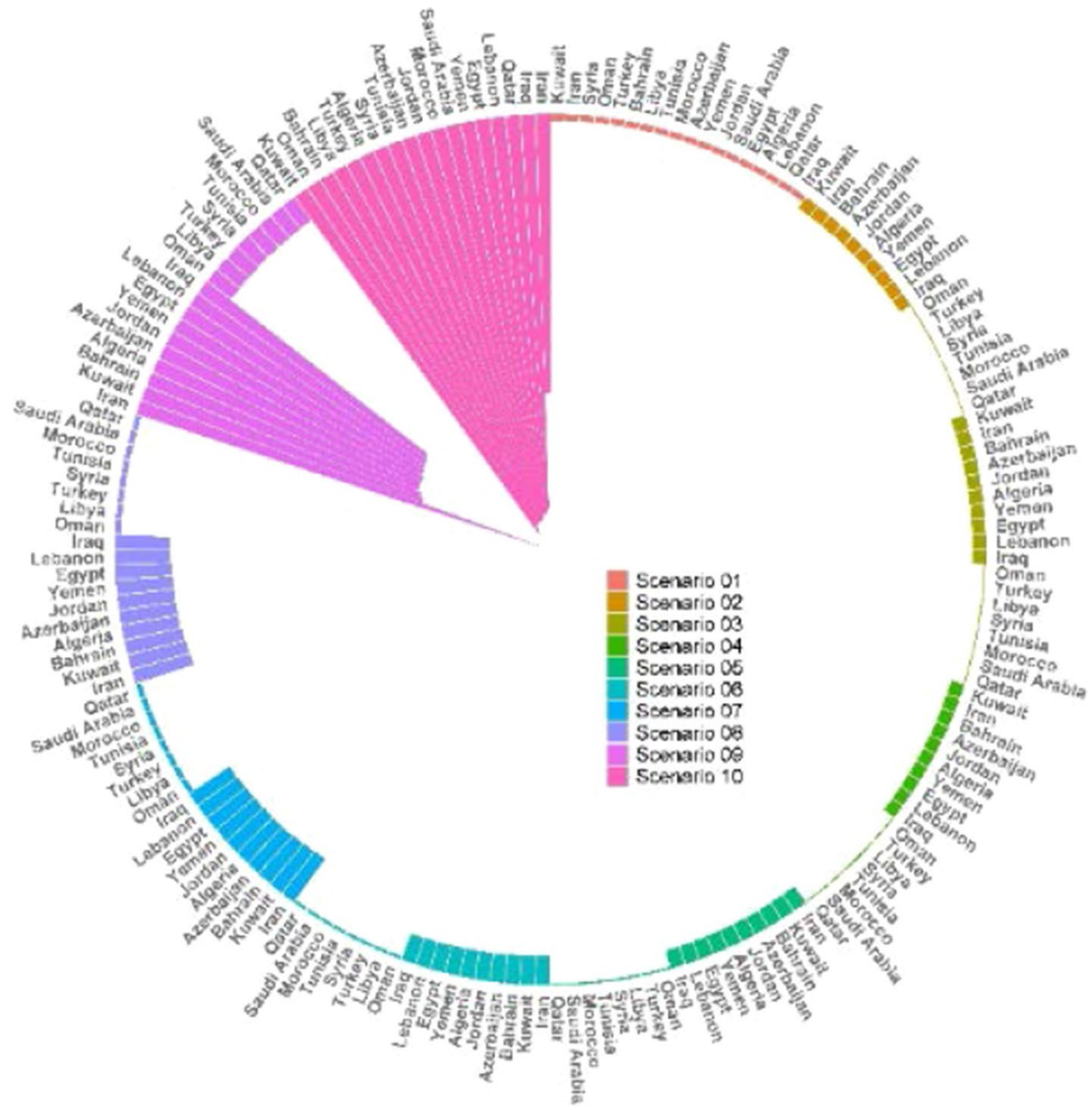

Fig. 28 GHG emission in sector 17. Source: Authors' calculations 


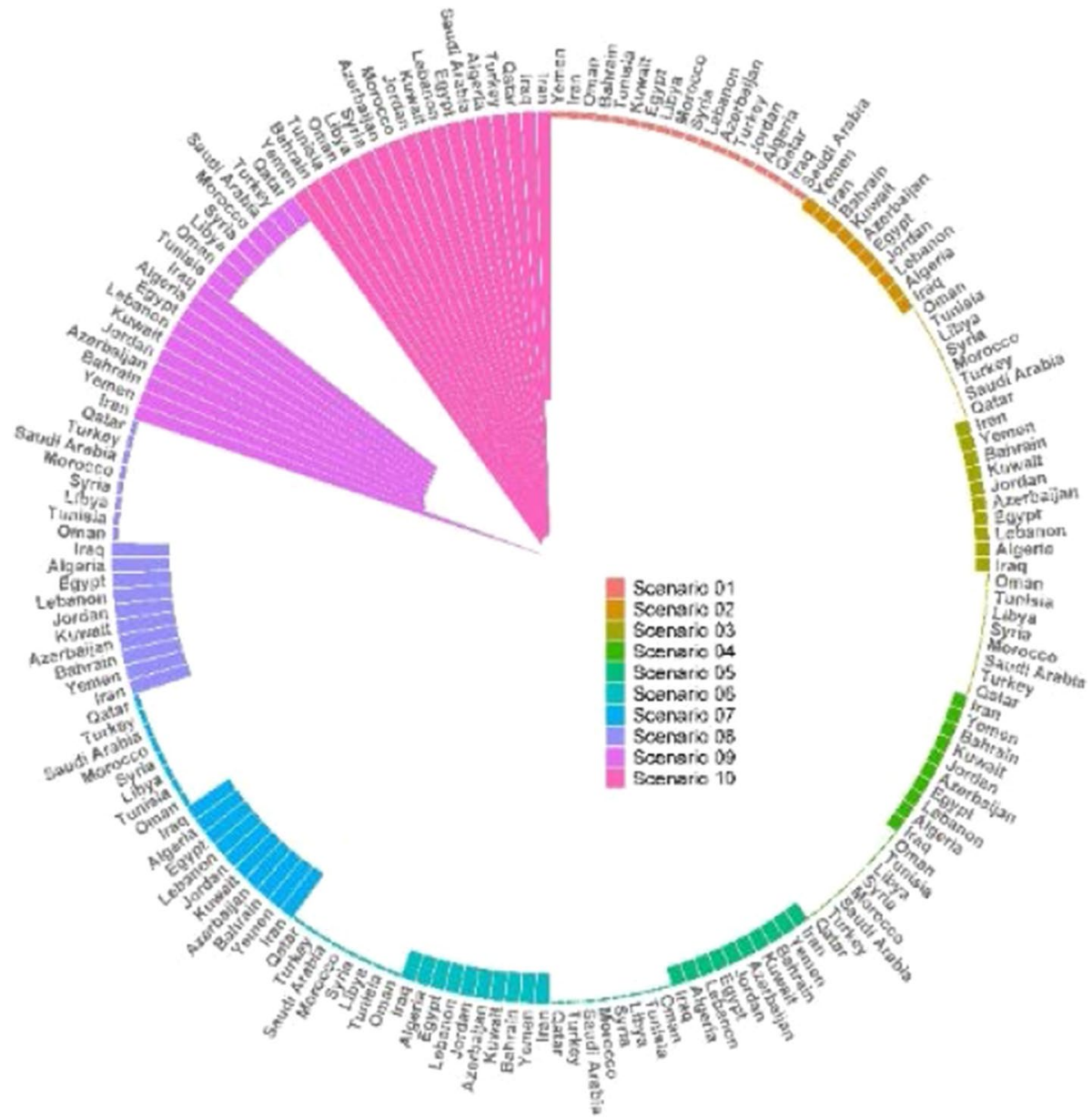

Fig. 29 GHG emission in sector 18. Source: Authors' calculations 


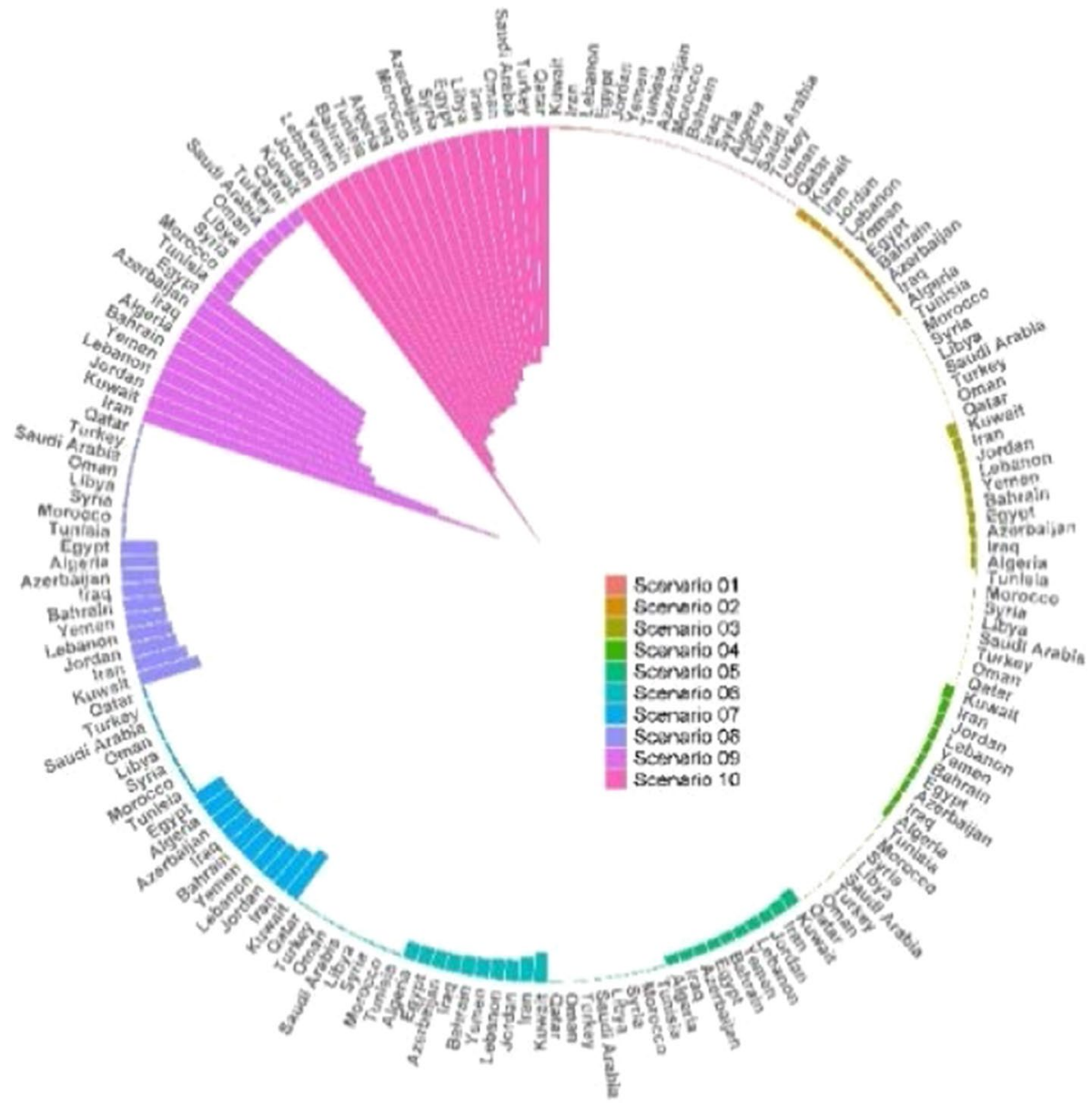

Fig. 30 GHG emission in sector 19. Source: Authors' calculations 


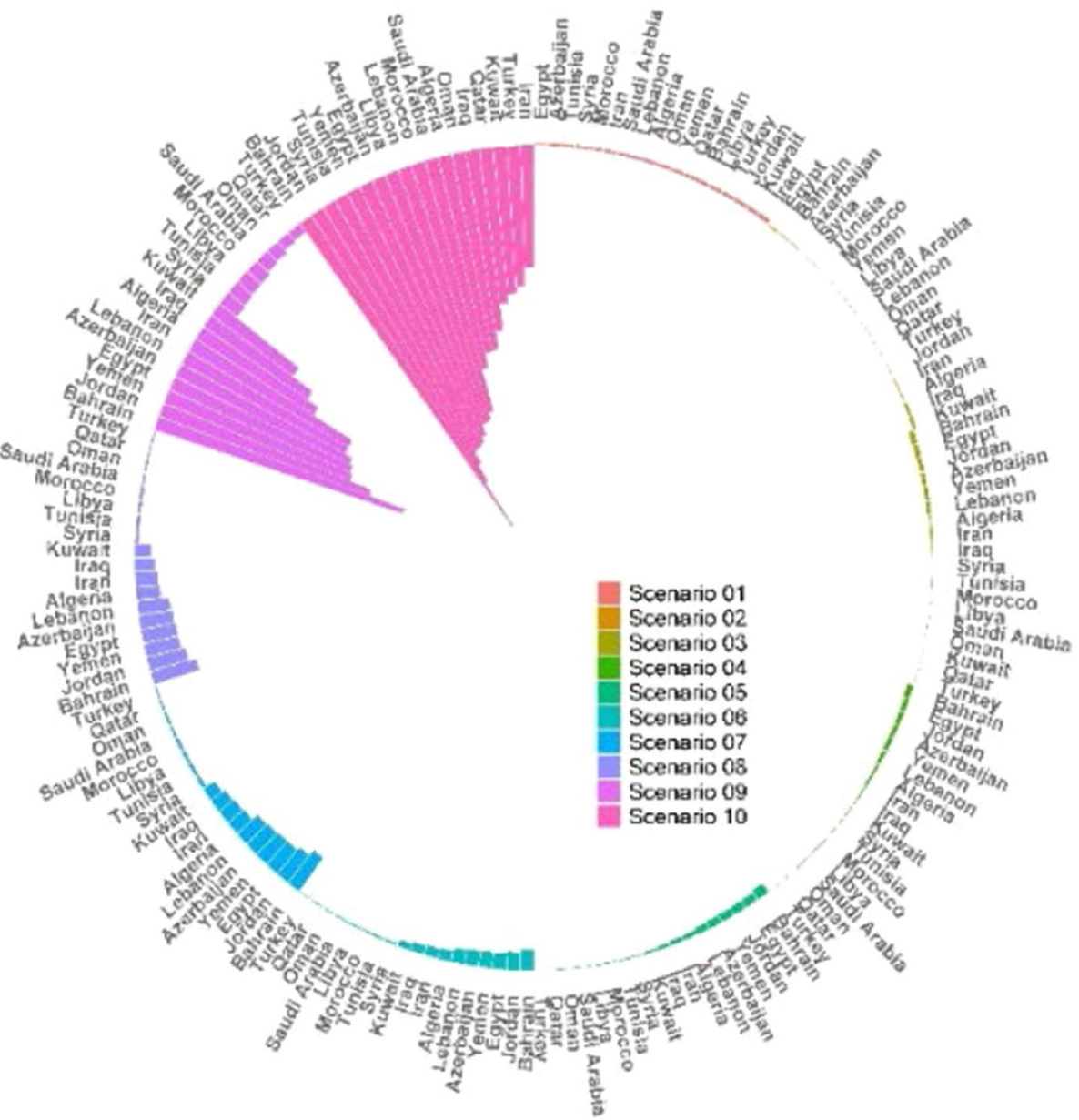

Fig. 31 GHG emission in sector 20. Source: Authors' calculations 


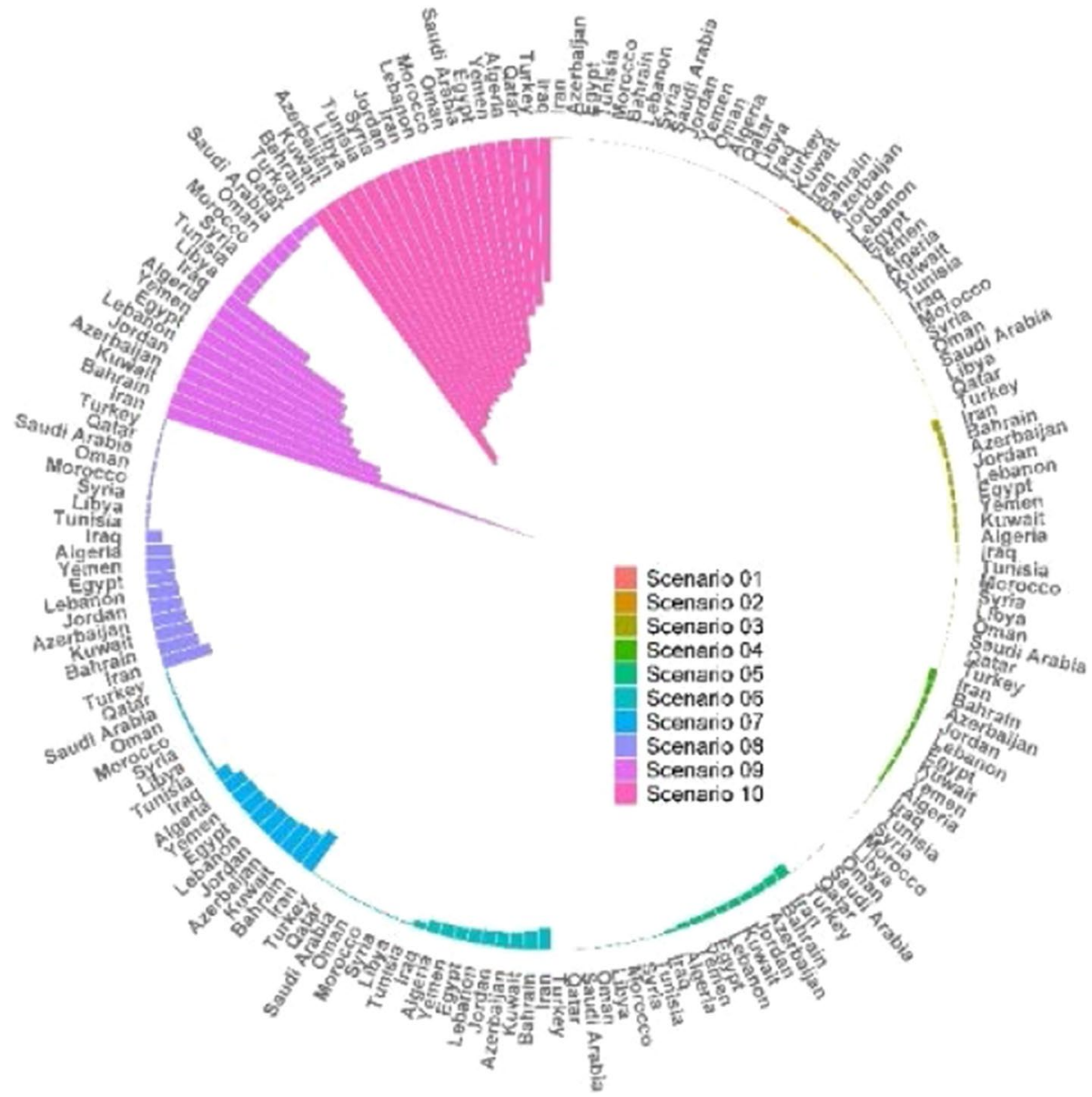

Fig. 32 GHG emission in sector 21. Source: Authors' calculations 


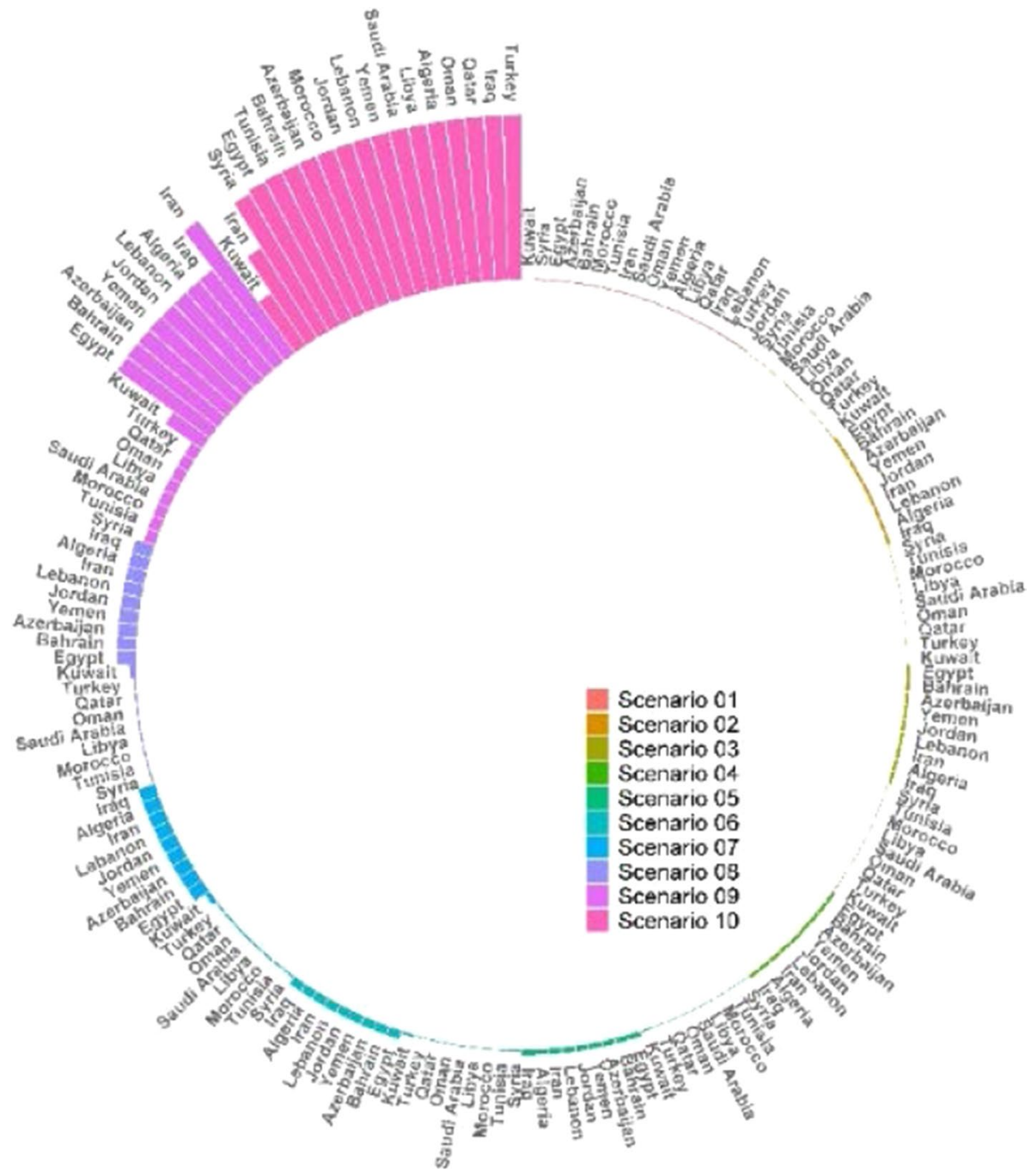

Fig. 33 GHG emission in sector 22. Source: Authors' calculations 


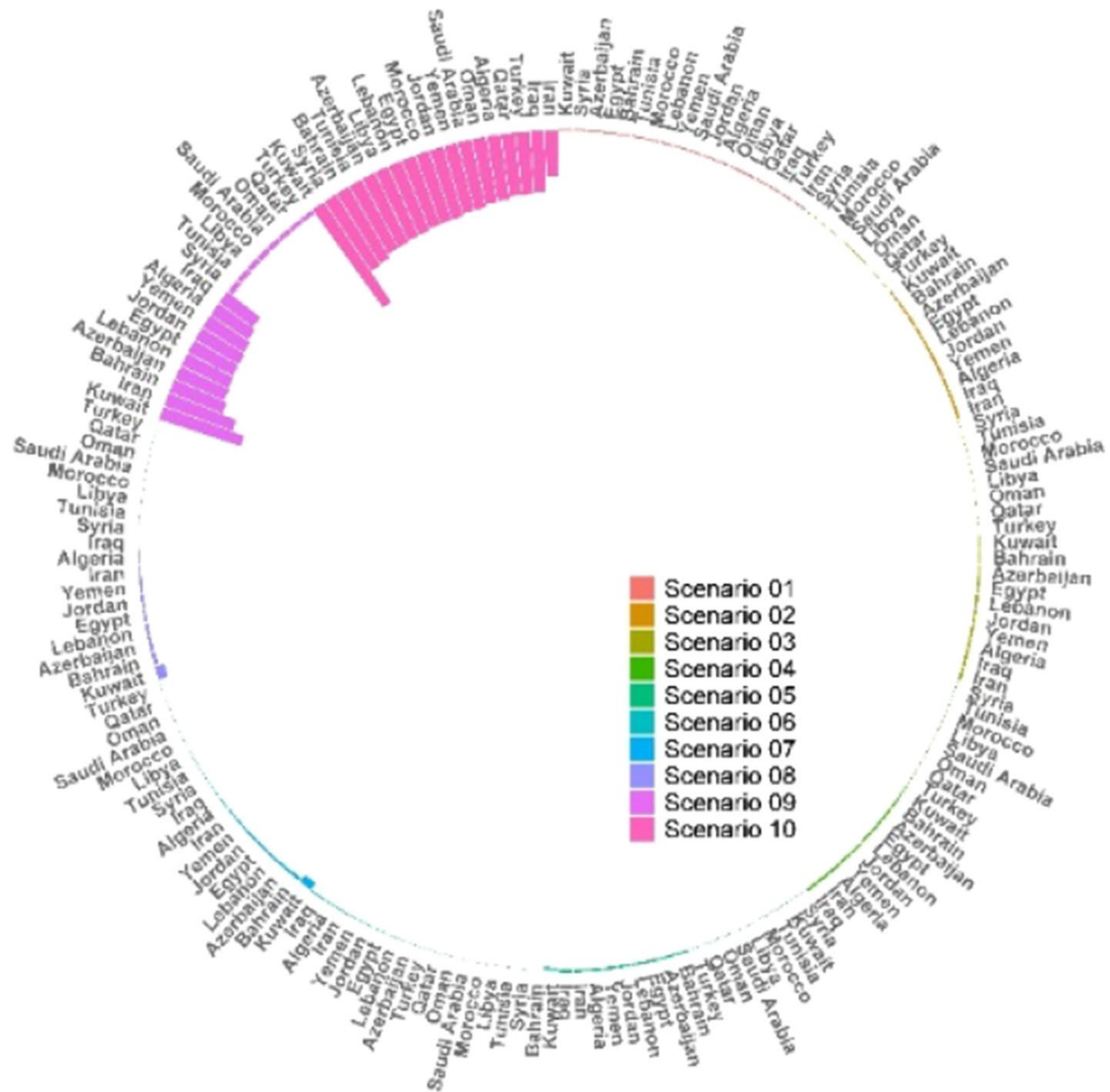

Fig. 34 GHG emission in sector 23. Source: Authors' calculations 


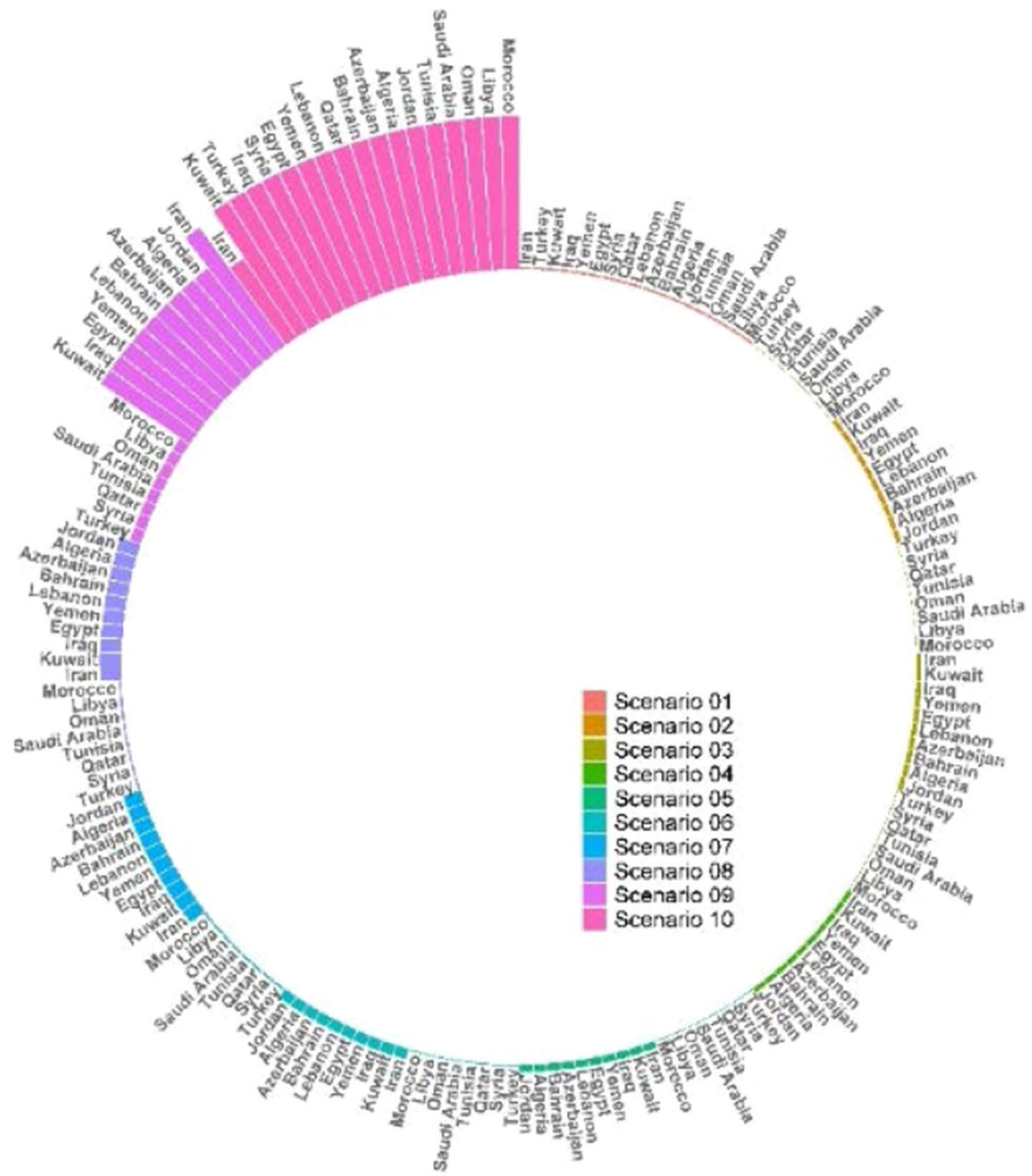

Fig. 35 GHG emission in sector 24. Source: Authors' calculations 


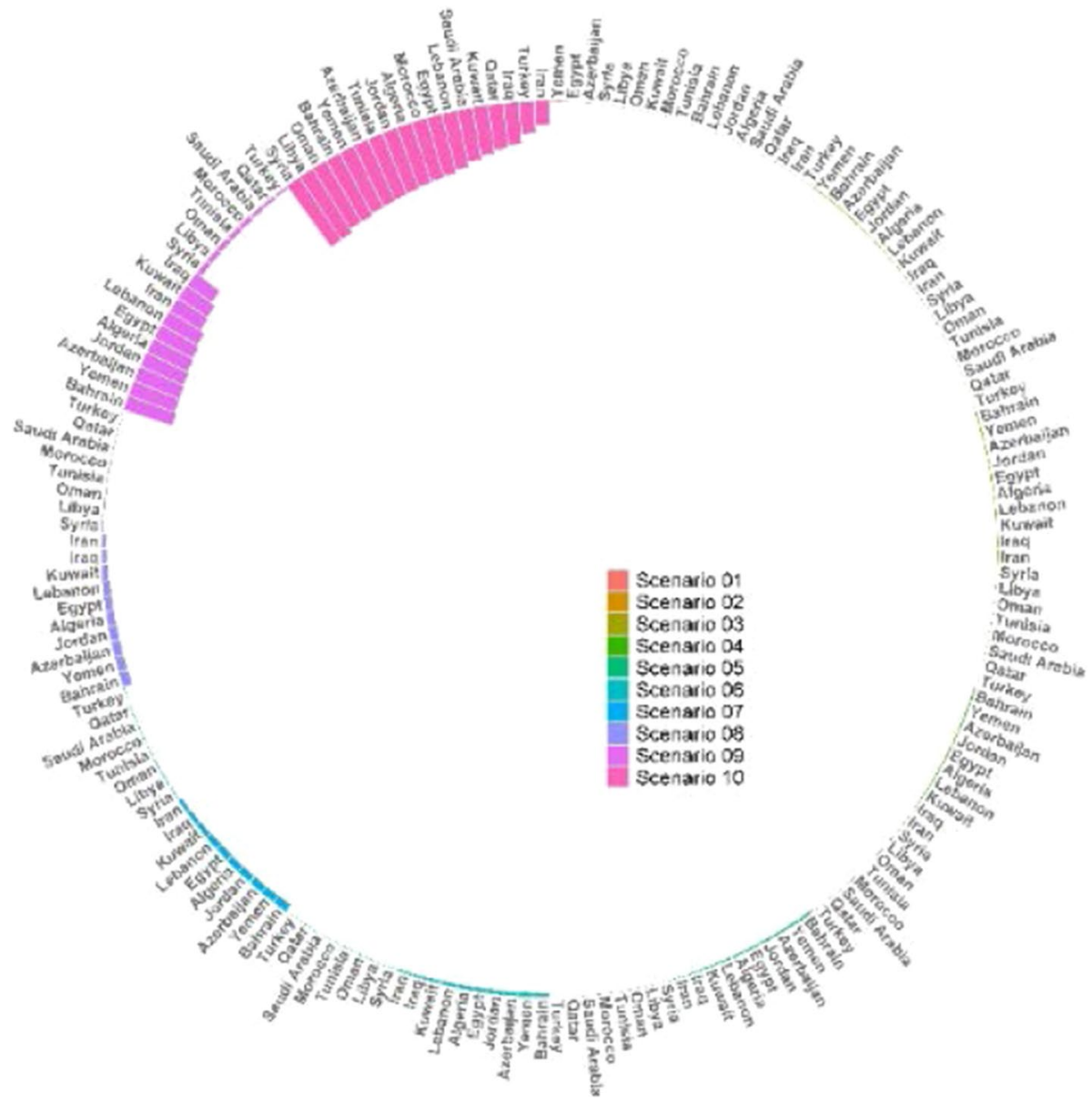

Fig. 36 GHG emission in sector 25. Source: Authors' calculations 


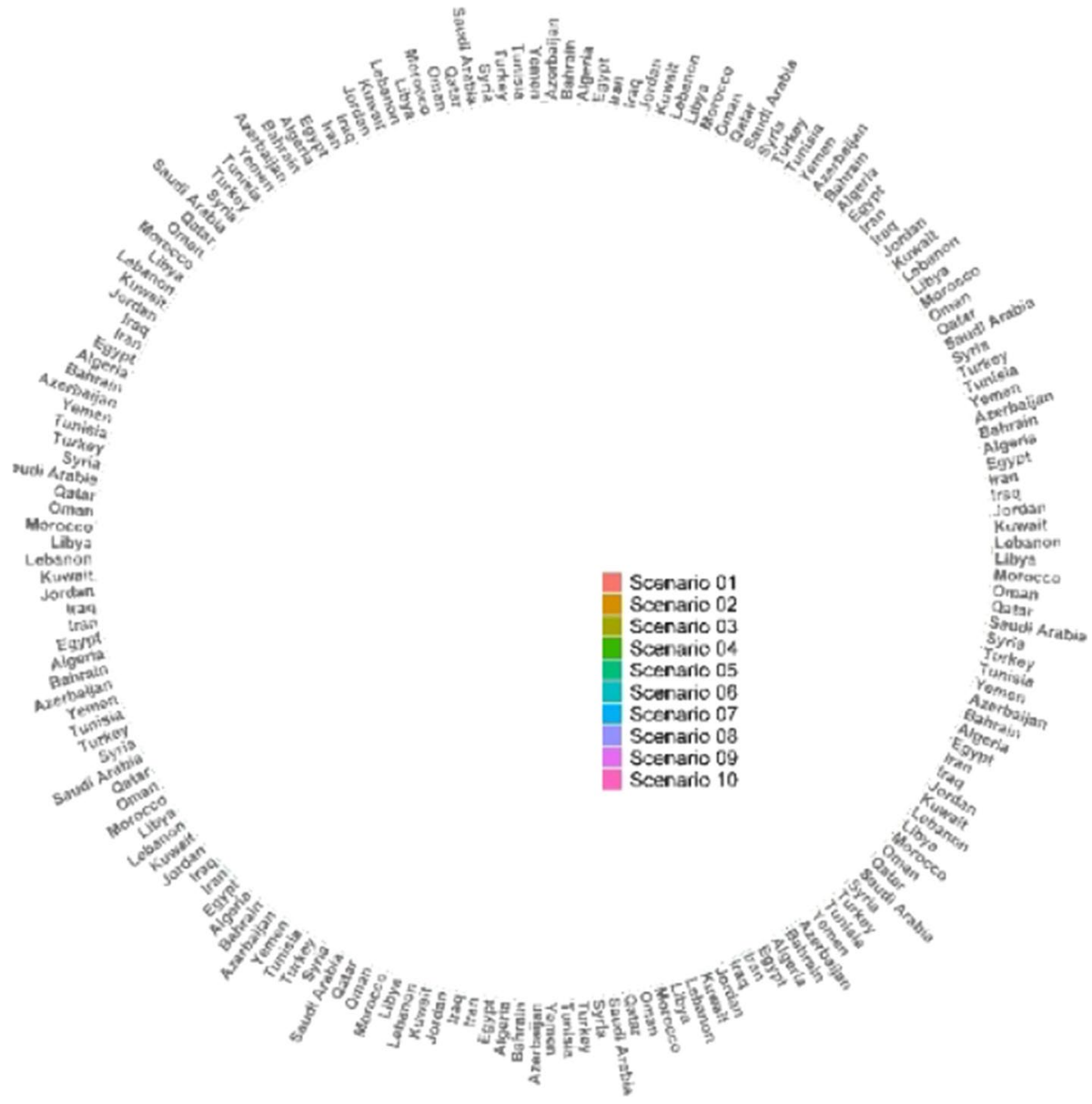

Fig. 37 GHG emission in sector 26. Source: Authors' calculations 


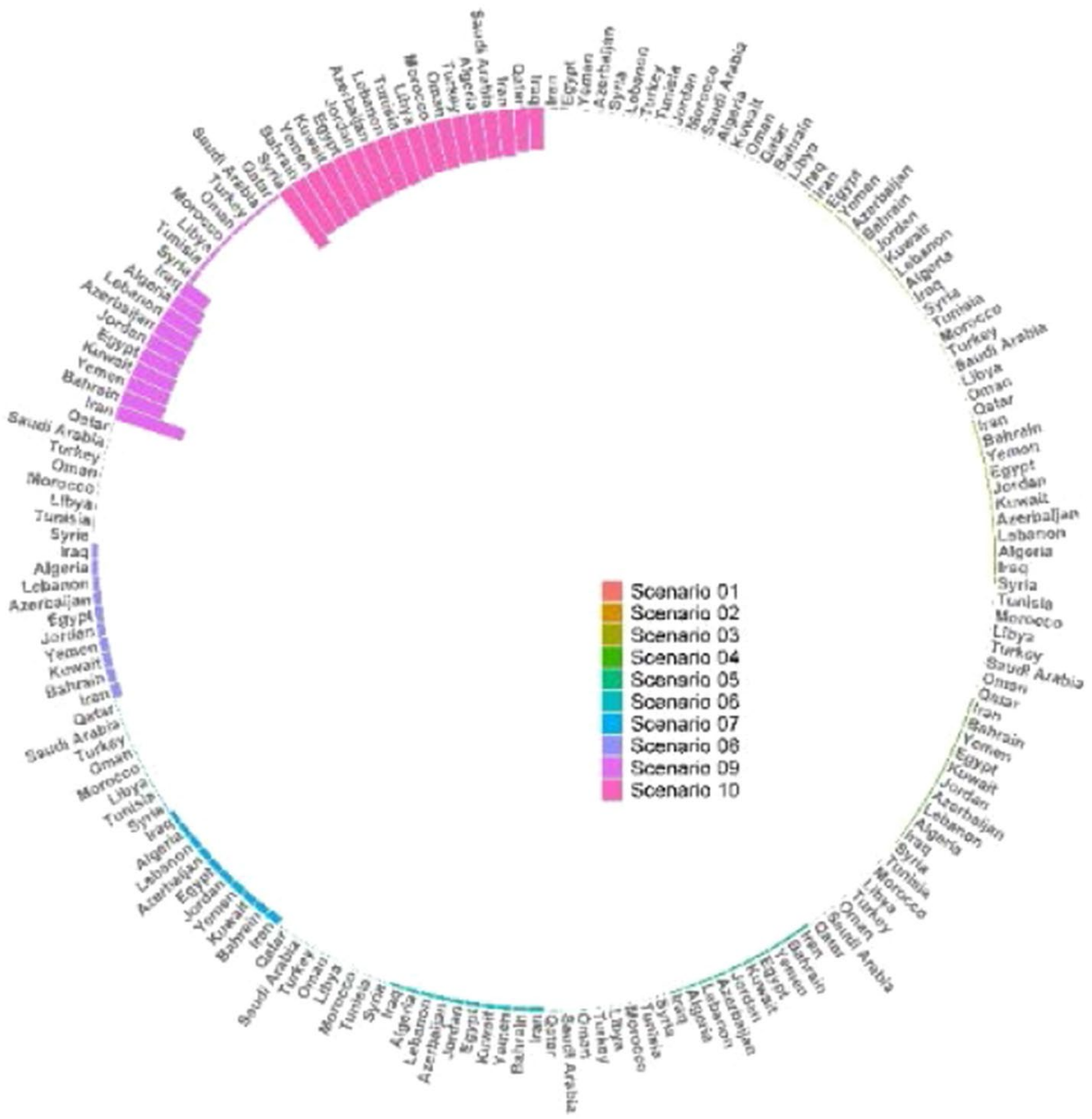

Fig. 38 GHG emission in final demand. Source: Authors' calculations

Supplementary Information The online version contains supplementary material available at https://doi. org/10.1007/s10668-021-02018-3.

Authors' contribution MGA contributed to conceptualization, methodology, data curation, software, writing — original draft preparation. SR contributed to validation, writing —original draft preparation, writing reviewing, and editing. MI contributed to validation, writing-original draft preparation, writing-reviewing, and editing. RR contributed to methodology, data curation, validation, and software. MGD contributed to visualization, writing - reviewing and editing, supervision.

Funding No funds, grants, or other support was received.

Data availability The datasets used during the current study are available from the corresponding or first author on reasonable request_https://doi.org/10.6084/m9.figshare.14128715.v3.

\section{Declarations}

Conflict of interest The authors declare that they have no known competing financial interests or personal relationships that could have appeared to influence the work reported in this paper. 


\section{References}

Althor, G., Watson, J. E., \& Fuller, R. A. (2016). Global mismatch between greenhouse gas emissions and the burden of climate change. Scientific Reports, 6(1), 1-6.

Aydin, G. (2014). Production modeling in the oil and natural gas industry: An application of trend analysis. Petroleum Science and Technology, 32(5), 555-564.

Aydin, G. (2015a). The application of trend analysis for coal demand modeling. Energy Sources, Part b: Economics, Planning, and Policy, 10(2), 183-191.

Aydin, G. (2015b). Forecasting natural gas production using various regression models. Petroleum Science and Technology, 33(15-16), 1486-1492.

Aydin, G. (2015c). The modeling and projection of primary energy consumption by the sources. Energy Sources, Part b: Economics, Planning, and Policy, 10(1), 67-74.

Aydin, G., Karakurt, I., \& Aydiner, K. (2012). Analysis and mitigation opportunities of methane emissions from the energy sector. Energy Sources, Part a: Recovery, Utilization, and Environmental Effects, 34(11), 967-982.

Azadeh, A., \& Tarverdian, S. (2007). Integration of genetic algorithm, computer simulation and design of experiments for forecasting electrical energy consumption. Energy Policy, 35(10), 5229-5241.

Baldwin, R., \& Di Mauro, B. W. (2020). The Economy in the Time of Covid-19. LAC Semiannual Report; April 2020. Washington, DC: World Bank.

Berhe, A., Bariagabre, S. A., \& Balehegn, M. (2020). Estimation of greenhouse gas emissions from three livestock production systems in Ethiopia. International Journal of Climate Change Strategies and Management. https://doi.org/10.1108/IJCCSM-09-2019-0060

Bhattacharyya, S. C. (2019). Energy economics: concepts, issues, markets and governance. Springer Nature.

Blewitt, J. (2012). Understanding sustainable development. Routledge.

Byravan, S., Ali, M. S., Ananthakumar, M. R., Goyal, N., Kanudia, A., Ramamurthi, P. V., \& Paladugula, A. L. (2017). Quality of life for all: A sustainable development framework for India's climate policy reduces greenhouse gas emissions. Energy for Sustainable Development, 39, 48-58.

CDP. (2020). The relationship between climate change and coronavirus (Covid-19). CDP Turkey. Retrieved April 20, 2020, from https://cdpturkey.sabanciuniv.edu/tr/content/iklim-coronavirus

Chichilnisky, G. (1997). What is sustainable development? Land Economics, 73, 467-491.

Ciaschini, M. (Ed.). (1988). Input-output analysis: current developments. Chapman and Hall.

Dietzenbacher, E., \& Lahr, M. L. (2013). Expanding extractions. Economic Systems Research, 25(3), 341-360.

Ding, T., Ning, Y., \& Zhang, Y. (2017). Estimation of greenhouse gas emissions in China 1990-2013. Greenhouse Gases: Science and Technology, 7(6), 1097-1115.

Doğan, B., Jebli, M. B., Shahzad, K., Farooq, T. H., \& Shahzad, U. (2020). Investigating the effects of meteorological parameters on COVID-19: case study of New Jersey, United States. Environmental Research, 191, 110148.

Elliott, J. (2012). An introduction to sustainable development. Routledge.

ESA. (2020). Coronavirus Lockdown Leading to Drop in Pollution across Europe. Eur. Sp. Agency. Retrieved April 20, 2020.

Eurostat. (2020). European Statistical Office. https://ec.europa.eu/eurostat.

Fatima, T., Shahzad, U., \& Cui, L. (2021). Renewable and nonrenewable energy consumption, trade and $\mathrm{CO} 2$ emissions in high emitter countries: Does the income level matter? Journal of Environmental Planning and Management, 64(7), 1227-1251.

Ghazouani, A., Jebli, M. B., \& Shahzad, U. (2021). Impacts of environmental taxes and technologies on greenhouse gas emissions: Contextual evidence from leading emitter European countries. Environmental Science and Pollution Research, 28(18), 22758-22767.

Ghazouani, A., Xia, W., Ben Jebli, M., \& Shahzad, U. (2020). Exploring the role of carbon taxation policies on $\mathrm{CO} 2$ emissions: Contextual evidence from tax implementation and non-implementation European Countries. Sustainability, 12(20), 8680.

Guo, J., Zhou, Y., Ali, S., Shahzad, U., \& Cui, L. (2021). Exploring the role of green innovation and investment in energy for environmental quality: An empirical appraisal from provincial data of China. Journal of Environmental Management, 292, 112779.

Haddad, E. A., Perobelli, F. S., \& de Araújo, I. F. (2020). Input-output analysis of COVID-19: methodology for assessing the impacts of lockdown measures. FEA/USP.

Hale, T., Webster, S., Petherick, A., Phillips, T., \& Kira, B. (2020). Oxford COVID-19 government response tracker (OxCGRT). Last updated, 8, 30.

Hale, T., Petherick, A., Phillips, T., \& Webster, S. (2020). Variation in government responses to COVID19. Blavatnik school of government working paper, 31, 2020-11. 
Hassan, M. S., Bhuiyan, M. A. H., Tanu, S. M., Tareq, M. F., Bodrud-Doza, M., \& Rabbani, K. A. (2020). Spatial relationships between COVID-19 infection rates and air pollution, geo-meteorological and social parameters in Dhaka, Bangladesh.

Hensher, D. A. (2008). Climate change, enhanced greenhouse gas emissions and passenger transport-What can we do to make a difference? Transportation Research Part d: Transport and Environment, 13(2), 95-111.

Iqbal, N., Fareed, Z., Wan, G., \& Shahzad, F. (2021). Asymmetric nexus between COVID-19 outbreak in the world and cryptocurrency market. International Review of Financial Analysis, 73, 101613.

Kaygusuz, K. (2009). Energy and environmental issues relating to greenhouse gas emissions for sustainable development in Turkey. Renewable and Sustainable Energy Reviews, 13(1), 253-270.

Köne, A. Ç., \& Büke, T. (2010). Forecasting of CO2 emissions from fuel combustion using trend analysis. Renewable and Sustainable Energy Reviews, 14(9), 2906-2915.

Küstermann, B., Kainz, M., \& Hülsbergen, K.-J. (2008). Modeling carbon cycles and estimation of greenhouse gas emissions from organic and conventional farming systems. Renewable Agriculture and Food Systems, 23(1), 38-52.

Kyung, D., Kim, M., Chang, J., \& Lee, W. (2015). Estimation of greenhouse gas emissions from a hybrid wastewater treatment plant. Journal of Cleaner Production, 95, 117-123.

Lenzen, M., Li, M., Malik, A., Pomponi, F., Sun, Y. Y., Wiedmann, T., \& Yousefzadeh, M. (2020). Global socio-economic losses and environmental gains from the Coronavirus pandemic. PLoS ONE, 15(7), e0235654.

Li, J., Tian, Y., Deng, Y., Zhang, Y., \& Xie, K. (2021). Improving the estimation of greenhouse gas emissions from the Chinese coal-to-electricity chain by a bottom-up approach. Resources, Conservation and Recycling, 167, 105237.

Liberalesso, T., Cruz, C. O., Silva, C. M., \& Manso, M. (2020). Green infrastructure and public policies: An international review of green roofs and green walls incentives. Land Use Policy, 96, 104693.

Liu, X., Hewings, G. J., Qin, M., Xiang, X., Zheng, S., Li, X., \& Wang, S. (2020). Modelling the situation of COVID-19 and effects of different containment strategies in China with dynamic differential equations and parameters estimation. Available at SSRN 3551359.

Lyeonov, S., Pimonenko, T., Bilan, Y., Štreimikienè, D., \& Mentel, G. (2019). Assessment of green investments' impact on sustainable development: Linking gross domestic product per capita, greenhouse gas emissions and renewable energy. Energies, 12(20), 3891.

McKibbin, W., \& Fernando, R. (2021). The global macroeconomic impacts of COVID-19: Seven scenarios. Asian Economic Papers, 20(2), 1-30.

Miller, R. E., \& Blair, P. D. (2009). Input-output analysis: Foundations and extensions. Cambridge University Press.

Mitra, A., Ray Chadhuri, T., Mitra, A., Pramanick, P., \& Zaman, S. (2020). Impact of COVID-19 related shutdown on atmospheric carbon dioxide level in the city of Kolkata. Parana Journal of Science and Education, 6(3), 84-92.

Monteith, H. D., Sahely, H. R., MacLean, H. L., \& Bagley, D. M. (2005). A rational procedure for estimation of greenhouse-gas emissions from municipal wastewater treatment plants. Water Environment Research, 77(4), 390-403.

Myllyvirta, L., \& Dahiya, S. (2020). India's Coronavirus Curfew Resulted in the Lowest One-Day Traffic Pollution Levels on Record. CREA. Centre for Research on Energy and Clean Air.

Preston, B. L., \& Jones, R. N. (2006). Climate change impacts on Australia and the benefits of early action to reduce global greenhouse gas emissions: CSIRO Canberra.

Rafique, M. Z., Doğan, B., Husain, S., Huang, S., \& Shahzad, U. (2021). Role of economic complexity to induce renewable energy: Contextual evidence from G7 and E7 countries. International Journal of Green Energy, 18(7), 745-754.

Rogers, P. P., Jalal, K. F., \& Boyd, J. A. (2012). An introduction to sustainable development. Earthscan.

Sachs, J. D. (2015). The age of sustainable development: Columbia University Press.

Sarkodie, S. A., \& Strezov, V. (2019). Effect of foreign direct investments, economic development and energy consumption on greenhouse gas emissions in developing countries. Science of the Total Environment, 646, 862-871.

Shahzad, F., Shahzad, U., Fareed, Z., Iqbal, N., Hashmi, S. H., \& Ahmad, F. (2020a). Asymmetric nexus between temperature and COVID-19 in the top ten affected provinces of China: A current application of quantile-on-quantile approach. Science of the Total Environment, 736, 139115.

Shahzad, U. (2020b). Environmental taxes, energy consumption, and environmental quality: Theoretical survey with policy implications. Environmental Science and Pollution Research, 27(20), 24848-24862. 
Shahzad, U., Ferraz, D., Doğan, B., \& do Nascimento Rebelatto, D. A. (2020c). Export product diversification and CO2 emissions: Contextual evidences from developing and developed economies. Journal of Cleaner Production, 276, 124146.

Shakoor, A., Chen, X., Farooq, T. H., Shahzad, U., Ashraf, F., Rehman, A., \& Yan, W. (2020). Fluctuations in environmental pollutants and air quality during the lockdown in the USA and China: Two sides of COVID-19 pandemic. Air Quality, Atmosphere and Health, 13(11), 1335-1342.

Shen, M., Huang, W., Chen, M., Song, B., Zeng, G., \& Zhang, Y. (2020). (Micro) plastic crisis: Un-ignorable contribution to global greenhouse gas emissions and climate change. Journal of Cleaner Production, 254, 120138.

Ståhl, G., Heikkinen, J., Petersson, H., Repola, J., \& Holm, S. (2014). Sample-based estimation of greenhouse gas emissions from forests - a new approach to account for both sampling and model errors. Forest Science, 60(1), 3-13.

Talbi, B., Jebli, M. B., Bashir, M. F., \& Shahzad, U. (2020). Does economic progress and electricity price induce electricity demand: A new appraisal in context of Tunisia. Journal of Public Affairs. https://doi. org/10.1002/pa.2379

Ten Raa, T. (2006). The economics of input-output analysis. Cambridge University Press.

Zuo, M. (2020). Coronavirus leaves China with mountains of medical waste. South China Morning Post.

Publisher's Note Springer Nature remains neutral with regard to jurisdictional claims in published maps and institutional affiliations. 